\title{
Impact of additive manufacturing on Engineering education - evidence from Italy
}

\begin{abstract}
Purpose

The purpose of this paper is to evaluate how the direct access to additive manufacturing (AM) systems impacts on education of future mechanical engineers, within a Master's program at a top Italian University.

Design/methodology/approach
\end{abstract}

A survey is specifically designed to assess the relevance of entry-level AM within the learning environment, as a tool for project development. The survey is distributed anonymously to three consecutive cohorts of students who attended the course of "Computer Aided Production (CAP)", within the Master of Science Degree in Mechanical Engineering at the Politecnico di Torino. The course includes a practical project, consisting in the design of a polymeric product with multiple components and ending with the production of an assembled prototype. The working assembly is fabricated by the students themselves, who operate a fused deposition modelling (FDM) machine, finish the parts and evaluate assemblability and functionality.

The post-course survey covers diverse aspects of the learning process, such as motivation, knowledge acquisition, new abilities and team-working skills. Responses are analysed in order to evaluate students' perception of the usefulness of additive technologies in learning product design and development.

Among the projects, one representative case study is selected and discussed along with costs and performances of AM devices for educational purposes in engineering.

\section{Findings}

Results of the research affirm a positive relationship of access to AM devices to perceived interest, motivation and ease of learning of mechanical engineering. Entry-level additive technologies offer a handson experience within academia, fostering the acquisition of technical knowledge.

\section{Research limitations/implications}

The survey is distributed to more than 200 students to cover the full population of the CAP course over three academic years. The year students participated in the CAP course is not tracked, because the instructor was the same and there were no administrative differences. For this reason, the survey administration might be a limitation of the current study. In addition to this, no gender distinction is made, because historically the percentage of female students in Mechanical Engineering courses is about $10 \%$ or lower. Although the answers to the survey are anonymous, only $37 \%$ of the students gave a feedback. Thus, on one hand impact assessment is limited to a sample of about $1 / 3$ of the complete population, but on the other hand the anonymity ensures randomization in the sample selection.

\section{Practical implications}

Early exposure of forthcoming designers to AM tools can turn into a "think-additive" approach to product design, that is a groundbreaking conception of geometries and product functionalities, leading to the full exploitation of the possibilities offered by additive technologies.

\section{Social implications}

Shared knowledge can act as a springboard for mass adoption of AM processes.

\section{Originality/value}

The advantages of adopting AM technologies at different levels of education, for diverse educational purposes and disciplines are well assessed in the literature. The innovative aspect of this paper is that the impact of AM is evaluated through a feedback coming directly from mechanical engineering students. 
Keywords: Additive Manufacturing, Fused Deposition Modelling, Education, Survey, Impact

\section{Introduction}

The scientific community addresses the recent diffusion of AM technologies as the third industrial revolution (The Economist, 2012). Along with wide-spreading entry-level 3D printers and with the development of user-friendly $\mathrm{CAD}$ applications, proposed even for tablets and to young children, the education of people to additive technologies will become essential also from a social, economic and environmental perspective (Huang et al., 2013, Wittbrodt et al., 2013). These technological innovations have the potential to change consumers' behaviour and attitude towards the purchase of goods and spare parts (Khajavi et al., 2014), especially of plastic ones. From the point of view of environmental sustainability, raw material consumption is also cut down by the absence of tooling, so that recycling operations are limited to wastes generated by a wrong design of the part or by a faulty machine (Le Bourhis et al., 2013). In the wake of other free sharing and unrestricted access initiatives, virtual 3D models of parts will soon be available for download from open 3D libraries (Zhang et al., 2013).

Prototyping approaches already revealed significant educational benefits in multidisciplinary engineering tasks (Aw et al., 2007). It is well agreed that innovative teaching methods are needed, in order to provide adequate span of knowledge and diverse capabilities to the soon-to-be engineers, who will work in a complex global context (Bidanda et al., 2006). Doctor Drake in his editorial presents a summary of examples about the use of AM in teaching anatomy(Drake and Pawlina, 2014). Eisenberg discusses how designers should concentrate in making the 3D printing technology productive also for children (Eisenberg, 2013). Buehler et al. describe the application of AM for customized learning aids for students with disabilities (Buehler et al., 2014).

Recently, Kostakis et al. have published a paper on the educational use of 3D printing at two high schools in Greece, including qualitative research based on a questionnaire on different aspects whose answers were limited to Yes/No choices (Kostakis et al., 2015). Education about AM at academic level is reported by Wong et al. through the presentation of several projects developed at the Additive Manufacturing Innovation Centre (AMIC) at Nanyang Polytechnic in Singapore (Wong et al., 2014).

Therefore, the advantages of adopting AM technologies at different levels of education are well assessed in the literature for diverse educational purposes and disciplines that are not limited to the engineering field. The innovative aspect of this paper is that the impact of AM is assessed through direct feedback from mechanical engineering students, who receive education about manufacturing technologies at the highest level before the world of work.

In Italy, the Politecnico di Torino is one of the three universities exclusively devoted to engineering and architecture education. A track of the Master of Science (MS) program in Mechanical Engineering is focused on manufacturing technologies, with a specific spot on the production of plastic components. In each academic year, the track enrols an average of 70 students and it is characterized by three compulsory courses: "Computer Aided Production (CAP)", "Numerical methods for product/process design" and "Molds and forming processes". The track is worth 28 academic credits for a total of 280 hours, including 110 hours of practice, based on the principles of project-based learning (Mills and Treagust, 2003). The practical activities of the three courses are correlated in an integrated Computer Aided environment for Design, Engineering and Manufacturing (CAD/CAE/CAM). The activities are aimed at developing complete projects, from the design of the fully functional plastic assembly, to the design of the injection mold, through process simulation to optimize moulding conditions. Students work in groups of five, formed by the professor according to the principles of co-operative learning (Oxford, 1997). For convenience, the main project is divided in three sub-projects to fit the topics of each single course. Within the CAP course, students acquire the concepts of Computer Aided Manufacturing and time-compression technologies. The instructor has 25 years' experience in the field of additive technologies and co-leads a research group focused on AM (Atzeni et al., 2010a, Atzeni et al., 2010b, Bassoli et al., 2012, Bassoli et al., 2007, Berti et al., 2010, Calignano et al., 2013, Gatto et al., 2012, Manfredi et al., 2013, Minetola and Iuliano, 2012, Minetola and Iuliano, 2014, Violante et al., 2007). In the CAP course students are taught the principles of design for additive fabrication (Becker et al., 2005, Hague et al., 2003a, Hague et al., 2003b) to be applied in the 40 practice hours.

Students are asked to "think additive", that is they have to select an existing plastic assembly and redesign it, to maximize the advantages in its additive fabrication (Gibson et al., 2010). Among the key principles is the reduction of the number of product components, by integrating hinges and other joints, while preserving the product functionality. If a proper clearance is provided at the joints, two or more parts can be fabricated as 
one by using AM technologies. In the case of the FDM technique, the clearance is needed both for preserving the proper joint mobility, and to allow for the deposition of the support material.

When the size of one part or assembly exceeds the building volume of the FDM machine, students are asked to think of adequate splitting and to design the reference and joining features between the sub-assemblies. In the same semester, in the practice of "Numerical methods for product/process design", students choose one of the components of the designed assembly and engineer the part by a concurrent CAE approach. They both work on structural models, using a finite element software, and they also optimize the injection moulding process, by simulating the filling and holding phases and by analysing resulting shrinkage and part deformation. The described sub-projects of the two courses are developed in the fall semester, at the same time and in a concurrent environment. Part design is recursively updated as required by the parallel analyses. The workflow of the complete project is summarized in Figure 1, wherein different colours indicate the three courses. In the spring semester, students deal with mold design and production. Apart from ANSYS software for finite element structural analysis, the whole project is developed in an integrated CAD/CAE/CAM environment, using release 20 of VISI ${ }^{\circledR}$ Suite software by Vero International. The VISI ${ }^{\circledR}$ software modules used throughout the project are in italics in Figure 1. 
Figure 1 Workflow of the project of the students

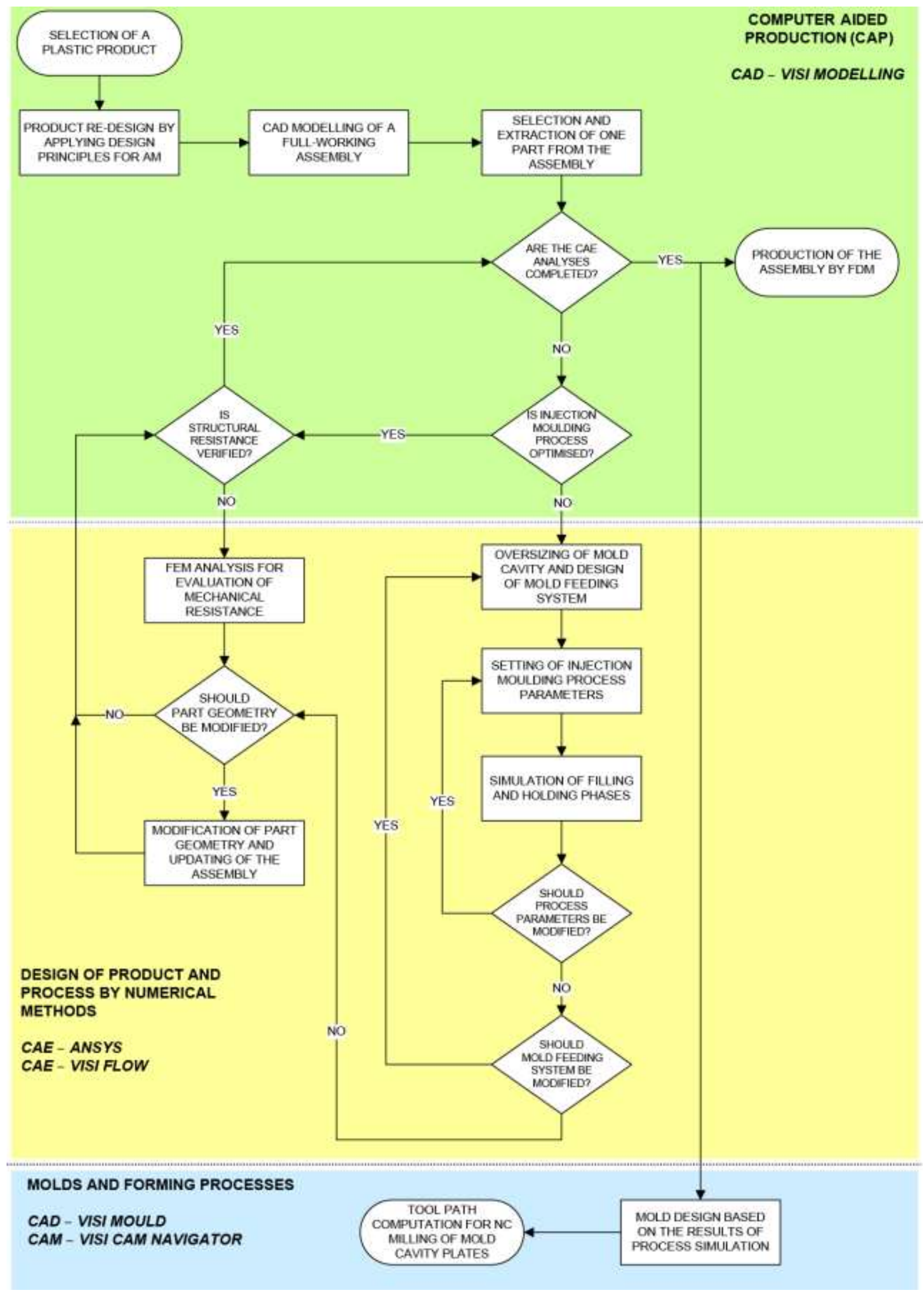


CAP students are given direct access to two FDM machines in the Rapid Manufacturing Laboratory (RMLab) of the Department of Management and Production Engineering (Politecnico di Torino): Dimension Elite $^{\mathrm{TM}}$ by Stratasys and 3D Touch ${ }^{\mathrm{TM}}$ by Bits from Bytes (3D Systems). The first has two extruders fed with the ABS build filament (1.75 mm diameter) and the soluble support material. Layer thickness is between .178 and $.254 \mathrm{~mm}$, working volume is $200 \times 200 \times 250 \mathrm{~mm}$ and the system costs about 20,000 euros. The second is an entry-level machine, now available on the market by 3D Systems for about 4,500 euros with the name CubeX ${ }^{\mathrm{TM}}$ Trio. The head is composed of three extruders fed with either ABS (build) or PLA (support) filaments ( $3 \mathrm{~mm}$ diameter), for deposition into a working volume of $185 \times 265$ × $240 \mathrm{~mm}$ with a layer thickness of $.125 \mathrm{~mm}, .250 \mathrm{~mm}$ or $.500 \mathrm{~mm}$.

Both machines allow the user to fabricate full working assemblies with integrated kinematic joints, as the support material is used to fill the gap corresponding to the clearance required for the correct motion. In the case of the CubeX ${ }^{\mathrm{TM}}$, PLA can be dissolved in ultrasonicated sodium hydrohide without damage to ABS. Moreover, multicolour or multi-material parts can be manufactured in one job by the entry-level FDM system, where as many as three filaments with different properties can be deposited in the same layer. Aim of this work is to evaluate the educational impact of entry-level AM systems, within a project-based learning environment, on the commitment, knowledge acquisition and abilities development of future mechanical engineers. For this purpose, a specific survey is designed and the responses of the students are analysed and discussed together with an example of best practice.

\section{The survey}

The survey was created by the authors and the final version distributed to the students was defined after discussion with colleagues who have teaching experience in manufacturing subjects within engineering courses. The survey consists of a compulsory section and an optional one. The compulsory section is designed to evaluate specific complementary aspects of the learning process, on a common basis for all the respondents. The use of the same evaluation levels on the same queries is required for a quantitative analysis of the responses. Students are asked to provide their level of agreement to a list of statements by using ticking boxes. The form can be submitted only once the compulsory section is fully completed. This limitation avoids incomplete feedbacks and ensures the same number of responses for all queries. The voluntary section is aimed at collecting individual comments or suggestions, freely expressed by those who feel like. Details of the two sections are given in the following.

\subsection{Compulsory section}

The compulsory section of the survey consists of twelve items. Each item is aimed at evaluating the impact of the access to AM devices during the CAP project under a different perspective. The aspects that are taken into consideration are listed hereafter.

1. Motivation: the direct use of AM systems could increase students motivation.

2. Understanding: the development of the project, involving the use of AM, could help in understanding the course topics.

3. Interest: the possibility to get the product manufactured by FDM could increase students' interest in the course topics.

4. Team working: students' skills related to team working could be increased by the use of AM during project development.

5. Impact: the use of AM could help conveying the course topics to the students.

6. Geometry: the production of parts by AM could help students in understanding the geometry of the product.

7. Assembly: the production of parts by AM could ease the comprehension of the assembly.

8. Functionality: the production of parts by AM could be explanatory of how the product works

9. Process: the use of an AM machine could help in understanding how layer fabrication proceeds

10. Education: the access to AM machines could increase students' perception of the importance of what they are learning

11. Lab practice: the use of AM devices could be felt as an opportunity to be suggested to others 
12. Modifications: the production of parts could be helpful in understanding possible design improvements.

One statement for each aspect is composed and proposed to the CAP students together with the above mentioned definition of the aspects. The statements that constitute the twelve items of the compulsory section are listed in Table I.

Table I Statements in the compulsory part of the survey

\begin{tabular}{|c|c|c|}
\hline Item & Aspect & Statement \\
\hline 1 & Motivation & The fabrication of designed parts increased your learning motivation \\
\hline 2 & Understanding & The project was helpful in understanding the course topics \\
\hline 3 & Interest & The project increased your interest in the course topics \\
\hline 4 & Team Working & The use of AM systems improved your team working skills \\
\hline 5 & Impact & You think you learnt more than if you only studied theory \\
\hline 6 & Geometry & You gained a better understanding of the geometry of parts \\
\hline 7 & Assembly & You better understood how the single parts assemble into the whole product \\
\hline 8 & Functionality & You gained a better understanding of the functionality of the whole product \\
\hline 9 & Process & $\begin{array}{l}\text { The direct use of the AM machine increased your understanding of the } \\
\text { principles of layer by layer fabrication }\end{array}$ \\
\hline 10 & Education & $\begin{array}{l}\text { The knowledge and skills obtained thanks to the project are relevant to your } \\
\text { educational objectives }\end{array}$ \\
\hline 11 & Lab Practice & $\begin{array}{l}\text { You would recommend the adoption of AM as a common tool for lab practice } \\
\text { in manufacturing technology courses }\end{array}$ \\
\hline 12 & Modifications & $\begin{array}{l}\text { If you had to design the part again after you got the additive manufactured } \\
\text { parts, you probably would have modified the part dimensions or tolerances }\end{array}$ \\
\hline
\end{tabular}

For the next analysis of the results, it is important to remark that each statement is formulated with a positive connotation, so the agreement with it implies a positive impact of the use of AM.

A 4-point Likert scale is used to produce a forced choice of the respondents between agreement and disagreement, where no indifferent option is available. Thus the four levels of agreement are defined as Strongly disagree, Disagree, Agree and Strongly agree; with no chance for a neutral response to the twelve items listed in Table I.

In the groups for the CAP practices, students self-organize the distribution of work, without restrictions by the instructor. Apart from rare cases of poor participation to the activities, each student is aware of the current state of the project and collaborates with the other group members. Typically, one or two members are more skilled in the use of CAD software then others, so they get in charge of design and 3D modelling activities. Other group members are more involved in parts' fabrication by FDM and in the post-finishing operations. Other members follow the project development and help the others without having a specific role. In order to evaluate if students' perception of the above aspects is influenced by the main role they took within the group, at the end of the compulsory section students are asked to state their role by selecting among the three following alternatives: 
What was your main role in the group?

- Mainly responsible for CAD design

- Mainly responsible for part production through Additive Manufacturing

- Just a participant (took part to the activities without a specific contribution to CAD design or part production)

\subsection{Voluntary section}

Five open questions are proposed to encourage expression of impressions, ideas and proposals about the use of AM technologies for the project of the CAP course.

The questions are listed in Table II, with a label stating the aspect they are intended to cover. The five aspects and relative questions are chosen to provide a direct feedback of students perceptions, integrating the quantitative compulsory section and extending the overview about the impact of additive manufacturing in mechanical engineering education.

Table II Open questions in the voluntary part of the survey

Nr. Aspect Question

\begin{tabular}{ll}
\hline Q1 Usefulness & $\begin{array}{l}\text { Think about what you have learnt through developing the project. What was the access } \\
\text { to additive manufacturing useful for? }\end{array}$ \\
Q2 Advantages & $\begin{array}{l}\text { What were the advantages of realizing a project that integrates mechanical design of } \\
\text { assemblies with their fabrication by additive technologies? }\end{array}$ \\
Q3 Drawbacks & What were the difficulties or drawbacks that you encountered? \\
Q4 Changes If you had the possibility to work on the project again, what would you change? & \\
Q5 Suggestions & What are your suggestions for the CAP practice in the years to come?
\end{tabular}

No limit is set on the number of the above questions that should be answered before submitting the form. Hence, students may decide to answer only some of the five questions and a different number of responses could be recorded for each aspect.

\section{Survey results}

The survey is distributed to the students on-line, by means of Google Forms, which is rather useful to collect the responses directly in an Excel file. The survey is administered outside class time, at the end of the course of the winter semester in 2014, to all the students enrolled in the CAP course over three consecutive academic years. No distinction is made about the academic year, because the instructor was the same and there were no administrative differences. Nevertheless, this way of administrating the survey could be a limitation of the current study. Owing to a large time span between the course experience and the survey administration, other experiences of the respondents might have influenced their understanding or perception of the technology. Thus, the methodology may have affected the results.

Results of the compulsory and voluntary sections are presented separately. All statistical analyses of the data collected in the compulsory section were carried out by means of R software.

\subsection{Compulsory section}

The invitation to take part to the survey is sent to all the students at the end of the course of the winter semester in 2014, with a reminder after two weeks from the first invitation. 82 feedbacks over 222 invitations are received, so the sample covers about $37 \%$ of the population.

Since the feedback is anonymous, the sample selection is randomized as in good statistical practice, so the results of the survey can be considered significant from a statistical point of view. No gender distinction is 
made, but it should be noticed that historically the percentage of female students in the MS Degree in Mechanical Engineering is about $10 \%$ or lower.

Among the 82 respondents, 44 students stated they were mainly involved in the CAD activity, 17 were mainly involved in additive manufacturing and 21 had no specific role within the work group. At a first glance, it might seem that the sample is not equally distributed among the three roles. However, since role definition is not formalized within the groups, it should be considered that a posteriori statements could be highly subjective. Moreover, there is no certainty of ratios among the roles in the population, which means that any distribution in the sample can be considered acceptable.

For the compulsory part of the survey, the responses collected from the 82 students are detailed by role in Table A1 of the Annexes, wherein percentages for each point of the Likert scale are detailed by role between brackets.

The results in the last column of Table A1 are aggregated without role distinction. They show that negative feedbacks are generally much rarer than positive ones. In addition, the majority of negative responses is not assertive, as it corresponds to Disagree level. A total consensus clearly emerges for Impact with 100\% of positive feedbacks. Only one negative response at Disagree level is obtained for Understanding.

This is well represented in Figure 2, wherein the proportion between agreement (Agree or Strongly Agree) and disagreement (Disagree or Strongly Disagree) is shown in terms of both number of responses and percentages, for each of the twelve statements and related aspects.

Figure 2 Proportion agreement/disagreement for the twelve items - aggregated view

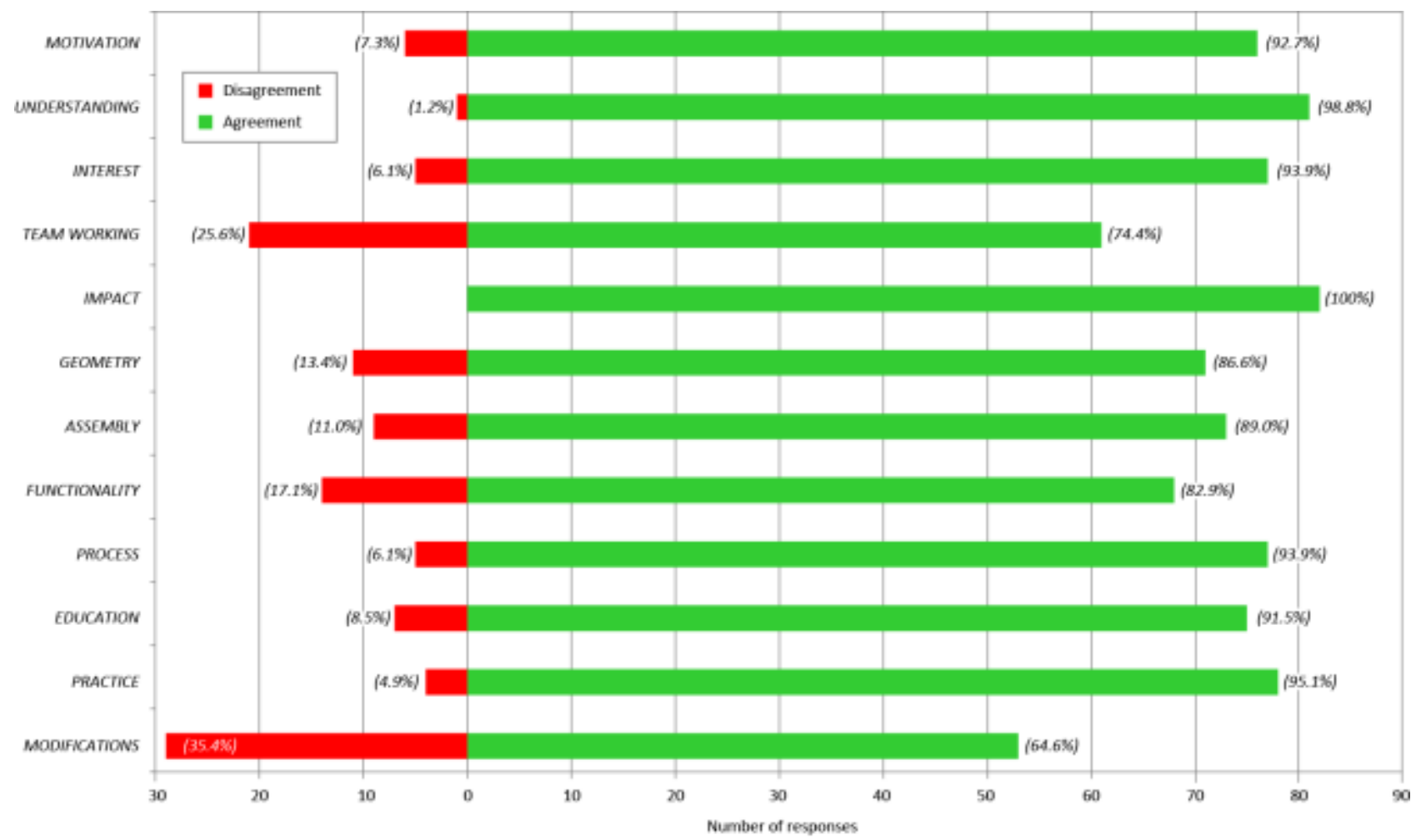

The level of agreement is greater than $90 \%$ for most of the statements, while that of Team Working and Modifications is lower than $80 \%$. An intermediate proportion between $80 \%$ and $90 \%$ is recorded for Assembly, Geometry and Functionality.

In the case of Team Working, the instructor does not become involved in the internal management of any group; students are left free of organizing themselves in any manner that they deem appropriate and attendance of students to the course practice is not strictly tracked. Difficulties in equal involvement of all members in the project can account for a higher percentage of disagreement for the improvement of team working skills through the adoption of AM.

As regards Modifications, about one third of the 82 students would not modify the dimensions or tolerances of their product after getting the additive manufactured parts. The design of the product was completed by following the guidelines of design for additive manufacturing, provided during the CAP course. A higher 
proportion of negative responses for this aspect means that such design activity led to satisfactory results from the point of view of dimensions, wall thicknesses and clearances. Owing to anonymity, unfortunately it is not possible to correlate the negative feedback to the complexity of the product that was developed by the group.

An error-free design of complex mechanical assemblies is excluded, because there are no other courses in the mechanical engineering program of the Politecnico di Torino that extend the engineering activities from the design of mechanical assemblies to the fabrication of the components. Within the assigned credits and hours, generally the design projects of other mechanical engineering courses are aimed at dimensioning and tolerancing parts and verifying their structural resistance analytically. Manufacturing constraints are considered, but then students do not have the possibility to fabricate the assembly and validate their design choices directly on the real parts.

Reasonably, it might be supposed that, if design mistakes are disregarded, no need for changes is associated to products that are less complex than others. As a matter of fact, more than one answer in the voluntary section reports difficulties that students encountered in correctly defining the tolerances for the moving parts of the assembly. Students also expressed their desire to modify the clearances for such parts in order to improve the part quality after looking at the additive manufactured assemblies. The reader is invited to refer to section 3.2 for more detail about this topic.

As concerns proportions, the number of positive and negative feedbacks for each item is detailed by student's role in table III.

Table III Number of positive and negative feedbacks - view by role

\begin{tabular}{|c|c|c|c|c|}
\hline \multirow{2}{*}{ Aspect } & \multirow{2}{*}{ Feedback } & \multicolumn{3}{|c|}{ Student's role } \\
\hline & & CAD & MANUF. & NO ROLE \\
\hline \multirow{2}{*}{ Motivation } & Agreement & 42 & 16 & 18 \\
\hline & Disagreement & 2 & 1 & 3 \\
\hline \multirow{2}{*}{ Understanding } & Agreement & 43 & 17 & 21 \\
\hline & Disagreement & 1 & 0 & 0 \\
\hline \multirow{2}{*}{ Interest } & Agreement & 41 & 17 & 19 \\
\hline & Disagreement & 3 & 0 & 2 \\
\hline \multirow{2}{*}{ Team Working } & Agreement & 34 & 13 & 14 \\
\hline & Disagreement & 10 & 4 & 7 \\
\hline \multirow{2}{*}{ Impact } & Agreement & 44 & 17 & 21 \\
\hline & Disagreement & 0 & 0 & 0 \\
\hline \multirow{2}{*}{ Geometry } & Agreement & 37 & 17 & 17 \\
\hline & Disagreement & 7 & 0 & 4 \\
\hline \multirow{2}{*}{ Assembly } & Agreement & 38 & 16 & 19 \\
\hline & Disagreement & 6 & 1 & 2 \\
\hline \multirow{2}{*}{ Functionality } & Agreement & 35 & 13 & 20 \\
\hline & Disagreement & 9 & 4 & 1 \\
\hline \multirow{2}{*}{ Process } & Agreement & 43 & 17 & 17 \\
\hline & Disagreement & 1 & 0 & 4 \\
\hline \multirow{2}{*}{ Education } & Agreement & 43 & 16 & 16 \\
\hline & Disagreement & 1 & 1 & 5 \\
\hline \multirow{2}{*}{ Lab Practice } & Agreement & 42 & 16 & 20 \\
\hline & Disagreement & 2 & 1 & 1 \\
\hline \multirow{2}{*}{ Modifications } & Agreement & 29 & 10 & 17 \\
\hline & Disagreement & 15 & 7 & 4 \\
\hline
\end{tabular}

For each aspect in table III, the corresponding 2 x 3 contingency table can be used to perform a Fisher exact probability test aiming at comparing the proportions among roles under the assumption of independence of the roles. The Chi square test cannot be used in this case because the contingency tables contain counts that are smaller than 5. The null hypothesis $\mathrm{H}_{0}$ that is considered for the test is that for the selected aspect, there is no difference in the proportion agreement/disagreement for the three roles. It means that students are equally likely to agree, no matter what their role in the CAP project is. With a significance level $\alpha$ of $5 \%$, we can reject the null hypothesis that there is no difference among roles only for Process ( $\mathrm{p}$-value $=.03$ ) and 
Education (p-value $=.01$ ). For all other aspects, we cannot reject the null hypothesis (p-value $>\alpha=.05$ ), thus no significant difference is observed in the proportion agreement/disagreement for the three roles.

Therefore in the case of Process and Education, the analysis can be deepened through a post-hoc Fisher exact probability test, limiting the comparison to only two roles at a time. Three tests are run for each aspect by extracting $2 \times 2$ contingency tables from the $2 \times 3$ tables considered above. For both Process and Education aspects, the null hypothesis cannot be rejected while comparing the roles of CAD versus Manufacturing and Manufacturing versus No Role. Significant difference is observed between CAD and No Role (p-value for Process $=.03$ and p-value for Education $=.01$ ).

Therefore, it can be concluded that, between any group pair, the difference in the proportion agreement/disagreement for any aspect is not statistically significant, with the exception of Process and Education, where students with no specific role expressed a higher percentage of disagreement if compared to those of the CAD role.

Further analysis of the collected data is carried out by coding the levels of the Likert scale, that is by assigning a numeric value to each of them. For each of the twelve items, the following values are assigned to the responses of students: 1 to Strongly Disagree, 2 to Disagree, 3 to Agree and 4 to Strongly Agree.

Individual responses are then treated as ordinal data, because it cannot be presumed that students perceive all intervals as equally wide, that is with equal differences between adjacent levels.

The internal reliability of a survey and its reproducibility are commonly checked by Cronbach's analysis (Moret et al., 1993). For our survey, a value of .84 is obtained for the standardized Cronbach's alpha with a 95\% confidence interval between .77 and .94 . The following rule of thumb is provided in the literature to classify the reliability: excellent if $\alpha>.90$, good if $\alpha>.80$, acceptable if $\alpha>.70$, questionable if $\alpha>.60$ and poor for $\alpha>0.50$. Thus, it can be concluded that the survey is reliable for internal consistency because alpha is larger than .70 .

The distribution of the level of agreement expressed by the students for each of the twelve aspects is shown in the bar charts of Figure 3. All distributions are left skewed and their normality is checked by applying the Shapiro-Wilk test with the null hypothesis $\mathrm{H}_{0}$ that data follow a normal distribution. At a significance level $\alpha$ of $5 \%$, we should reject the null hypothesis for all the aspects, since the p-value from the Shapiro-Wilk test is much smaller than .05. Thus, non-parametric tests and methods have to be used to further analyse the survey data.

Figure 3 Bar charts for the twelve items
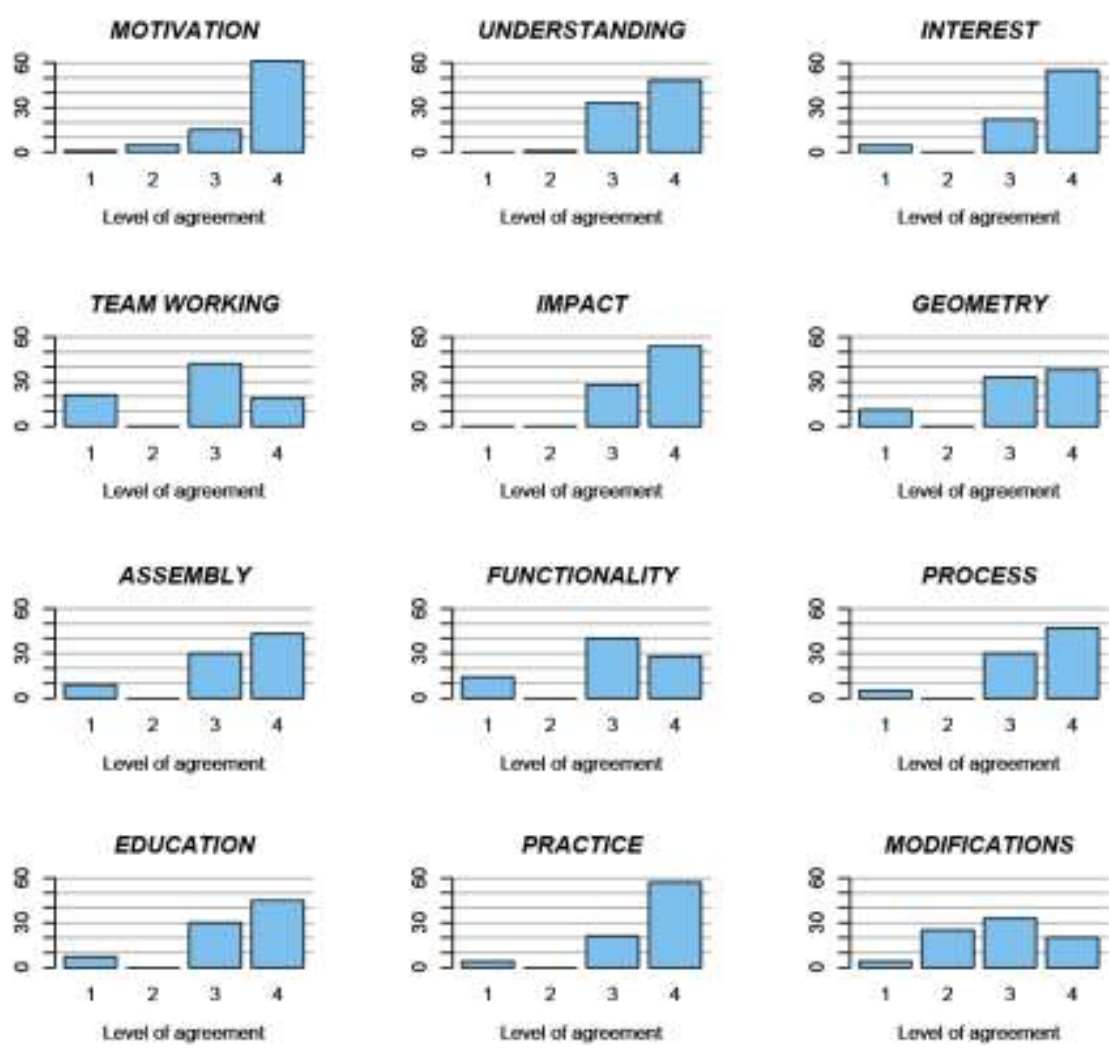
Basic descriptive statistics of the survey data are reported in table IV. In accordance with the positive proportion of responses in Figure 2, the median is high for all aspects. A median equal to 3 points of the Likert scale is obtained for Team Working, Geometry, Functionality and Modifications. These aspects are characterized by a positive proportion lower than $85 \%$ in Figure 2 . All other aspects have a median equal to the maximum of the Likert scale and a positive proportion higher than $85 \%$. More disperse results are observed for Geometry, Functionality and Modifications, whose median absolute deviation (MAD) is 1.48. The MAD is similar to the standard deviation and it is considered a very robust estimator of statistical dispersion for non-normally distributed data.

A tighter score range is recorded for Understanding and Impact, in accordance with the great positive proportions in Figure 2, of $98.8 \%$ and $100 \%$ respectively. The skewness values are negatives for all aspects, because the distributions of the level of agreement are not symmetric as already shown in Figure 3. Kurtosis values are associated with the peakedness of the distributions and non-null kurtosis confirms once again that all data is non-normally distributed.

Table IV Descriptive statistics of the survey data

\begin{tabular}{lcccc}
\hline Aspect & Median & $\begin{array}{c}\text { Median } \\
\text { Absolute } \\
\text { Deviation }\end{array}$ & Skewness & Kurtosis \\
\hline Motivation & 4 & 0 & -1.91 & 3.17 \\
Understanding & 4 & 0 & -0.55 & -1.15 \\
Interest & 4 & 0 & -2.03 & 3.81 \\
Team Working & 3 & 0 & -0.62 & -0.98 \\
Impact & 4 & 0 & -0.66 & -1.59 \\
Geometry & 3 & 1.48 & -1.23 & 0.49 \\
Assembly & 4 & 0 & -1.42 & 1.15 \\
Functionality & 3 & 1.48 & -0.97 & -0.14 \\
Process & 4 & 0 & -1.71 & 2.88 \\
Education & 4 & 0 & -1.57 & 1.93 \\
Practice & 4 & 0 & -2.18 & 4.8 \\
Modifications & 3 & 1.48 & -0.17 & -0.82 \\
\hline
\end{tabular}

For sake of completeness, the descriptive statistics for the data split by role are reported in the tables A2, A3 and A4 of the annexes for CAD, Manufacturing and No Role, respectively. For reasons of conciseness, the values in tables A2, A3 and A4 are not described in detail, but a comparison among different groups is carried out below.

The Kruskal-Wallis one-way analysis of variance by ranks can be used for testing whether, within each aspect, responses from students having different roles originate from the same distribution. It is used for comparing more than two groups that are independent and have different sample sizes. The null hypothesis $\mathrm{H}_{0}$ of the Kruskal-Wallis test is that the medians of all groups are equal, and the alternative hypothesis is that at least one population median of one group is different from the population median of at least one other group.

The results of the Kruskall-Wallis test for the three groups of role are reported in terms of p-value in the second column of table V. Assuming a significance level $\alpha$ of 5\%, the null hypothesis has to be rejected for the following aspects: Motivation, Understanding, Interest and Process. For these aspects it can be stated that the median of the responses of at least one of the roles is different from the medians of the responses of another role. The inference is that the medians differ, but to know to which pair(s) we can attribute this to, the post-hoc Dunn test should be carried out. Results of the Dunn test are summarized in table V for a significance level $\alpha$ of $5 \%$ and allow distinguishing between pairs.

As concerns Motivation, significant difference for the median is observed only between the CAD role and students taking no specific role inside the groups. Moreover, the medians of both CAD role and Manufacturing role are significantly different to those of students having no specific role for Understanding, Interest and Process aspects. On the contrary, for these aspects no significant difference in the median emerges when comparing the $\mathrm{CAD}$ role to the Manufacturing. 
Table V Results (p-values) of Kruskal-Wallis test and post-hoc Dunn test

\begin{tabular}{|c|c|c|c|c|}
\hline Aspect & $\begin{array}{c}\text { Kruskal-Wallis } \\
\text { test }\end{array}$ & CAD - Manufacturing & $\begin{array}{l}\text { Post-hoc Dunn test } \\
\text { CAD - No Role }\end{array}$ & Manufacturing - No Role \\
\hline Motivation & $.015^{* *}$ & .121 & $.002^{* *}$ & .095 \\
\hline Understanding & $.007 * *$ & .369 & $.001 * *$ & $.014 * *$ \\
\hline Interest & $.029 * *$ & .394 & $.001 * *$ & $.013 * *$ \\
\hline Team Working & .125 & - & - & - \\
\hline Impact & .273 & - & - & - \\
\hline Geometry & .181 & - & - & - \\
\hline Assembly & .443 & - & - & - \\
\hline Functionality & .647 & - & - & - \\
\hline Process & $.003 * *$ & .356 & $.001 * *$ & $.002 * *$ \\
\hline Education & .053 & - & - & - \\
\hline Practice & .387 & - & - & - \\
\hline Modifications & .491 & - & - & - \\
\hline
\end{tabular}

** Significant for $\alpha=.05$

The picture that emerges from these latest results is that those students who have an undefined role in the CAP groups are less committed to the project and they reasonably appear less motivated than others. Their choice not to assume a specific role inside the group could also derive from a limited interest of the single student towards the course topics. A lack in the ability of the professor to make the topics interesting and attractive for the student has to be excluded. In fact the evaluation that is made by students at the end of the course about the teaching skills of the professor has always been positive and has never raised similar issues. As a consequence of their poorer participation and involvement, students taking no specific role within the CAP groups report a weaker agreement about the positive influence that the adoption of AM technologies has on understanding the course topics (Understanding) and on realizing how the FDM process works (Process).

Finally, to look for linear association between pairs of different aspects within each role, the Kendall's tau $(\tau)$ correlation coefficients are considered for ordinal data. For this analysis, the level of significance $\alpha$ is raised to $1 \%$ in order to reduce the number of significant results focusing the discussion on most significant ones, which are highlighted with bold fonts in the following tables VI, VII and VIII. A minimum absolute value of .60 is assumed for the $\tau$ coefficient of pairs of aspects to be discussed, so to restrain the discussion to those pairs whose two-way relationship is moderate or stronger. Nevertheles,s interpreting the correlation coefficient in the case of ordinary data is not an easy task and the discussion that follows is proposed by the authors according to their own opinion and perception without no ambition to be fully shared by the reader. The correlation table for the CAD role is reported in table VI.

Table VI Correlation table for CAD role

\begin{tabular}{|c|c|c|c|c|c|c|c|c|c|c|c|}
\hline & 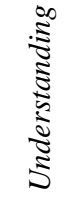 & $\begin{array}{l}\bar{\bigsqcup} \\
\stackrel{\Xi}{\Xi} \\
\Xi\end{array}$ & 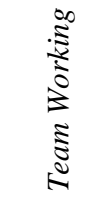 & 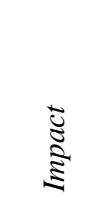 & 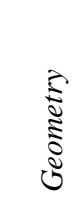 & 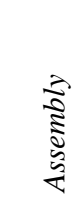 & 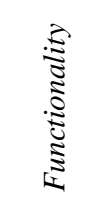 & 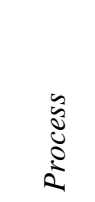 & 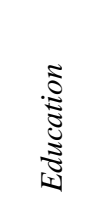 & 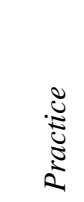 & 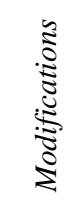 \\
\hline Motivation & .35 & $.56^{* *}$ & .30 & .36 & .30 & .24 & .32 & .26 & $.49 * *$ & .40 & .01 \\
\hline Understanding & & .24 & $.46 * *$ & $.50 * *$ & $.48^{* *}$ & $.58 * *$ & $.53 * *$ & .39 & .23 & $.78^{* *}$ & .21 \\
\hline Interest & & & .19 & .38 & .40 & $.42 * *$ & .39 & .38 & $.73 * *$ & $.42 * *$ & -.10 \\
\hline Team Working & & & & .19 & .38 & .17 & .26 & .12 & .18 & .35 & .07 \\
\hline Impact & & & & & .29 & .33 & $.42 * *$ & .33 & .40 & $.59 * *$ & -.14 \\
\hline Geometry & & & & & & $.67^{* *}$ & $.65 * *$ & $.43 * *$ & .24 & $.45 * *$ & -.09 \\
\hline Assembly & & & & & & & $.58 * *$ & .40 & .23 & $.54 * *$ & -.01 \\
\hline Functionality & & & & & & & & $.47 * *$ & .38 & $.50 * *$ & .04 \\
\hline Process & & & & & & & & & $.43 * *$ & $.45^{* *}$ & .15 \\
\hline Education & & & & & & & & & & .29 & .04 \\
\hline Practice & & & & & & & & & & & .02 \\
\hline
\end{tabular}


A moderate $(\tau>.60)$ to strong $(\tau>$.80) linear association is statistically significant for the following pairs: Understanding-Practice $(\tau=.78)$, Interest-Education $(\tau=.73)$, Geometry-Assembly $(\tau=.67)$ and Geometry-Functionality $(\tau=.65)$.

The strong correlation Understanding-Practice with respect to the use of AM technologies suggest a "learn by doing" interpretation by those students who took the active CAD role. For these students a rather moderate relationship is also statistically significant between Interest and Education. A positive influence of AM technologies on their interest (Interest) toward the CAP course topics also reflects in a better compliance with their educational objectives (Education) and vice versa.

A moderate correlation emerges for the pairs Geometry-Assembly and Geometry-Functionality as well. With reference to table VI, the third pair Assembly-Functionality $(\tau=.58)$ is also statistically significant among other pairs with correlation values close to the assumed threshold. For students that are voluntarily in charge of the CAD design, the adoption of AM technologies for the PAC project improves the understanding of the geometry of parts, of their assemblability and of the product's functionality. Indeed these three concepts are interrelated in mechanical design of complex assemblies.

The correlation table for the Manufacturing role is reported in table VII.

Table VII Correlation table for Manufacturing role

\begin{tabular}{|c|c|c|c|c|c|c|c|c|c|c|c|}
\hline & 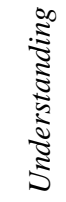 & 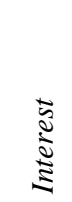 & 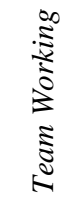 & $\begin{array}{l}\overleftarrow{\Xi} \\
\stackrel{\Xi}{\Xi} \\
\stackrel{\Xi}{\Xi}\end{array}$ & 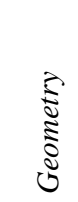 & 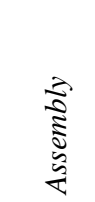 & 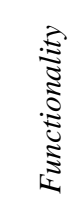 & $\begin{array}{l}\tilde{y} \\
\stackrel{0}{0} \\
=\end{array}$ & 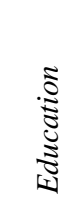 & 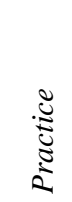 & 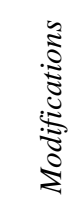 \\
\hline Motivation & .35 & .57 & .58 & .35 & .35 & .30 & .35 & -.06 & .45 & .39 & .20 \\
\hline Understanding & & .46 & .10 & .23 & -.29 & -.04 & -.10 & .06 & .11 & .28 & -.26 \\
\hline Interest & & & .43 & $.75 * *$ & .25 & .43 & .23 & -.05 & .12 & .49 & .06 \\
\hline Team Working & & & & .27 & .60 & .45 & .56 & -.24 & .44 & .58 & .33 \\
\hline Impact & & & & & .20 & .18 & .06 & .06 & .11 & .28 & -.12 \\
\hline Geometry & & & & & & $.76^{* * *}$ & .39 & -.17 & .42 & .12 & .41 \\
\hline Assembly & & & & & & & .43 & -.04 & .49 & .30 & .31 \\
\hline Functionality & & & & & & & & .23 & .42 & .56 & .47 \\
\hline Process & & & & & & & & & -.12 & .11 & -.24 \\
\hline Education & & & & & & & & & & .24 & .25 \\
\hline Practice & & & & & & & & & & & .06 \\
\hline
\end{tabular}

A moderate $(\tau>.60)$ to strong $(\tau>.80)$ linear association is statistically significant for Interest-Impact $(\tau=$ $.75)$ and Geometry-Assembly $(\tau=.76)$. Thus in the case of students taking care of parts manufacturing, the correlation analysis suggests that the use of AM technologies helps them to learn more than if they only studied theory (Impact) and this reflects also on their interest (Interest) towards the CAP course topics. Moreover, for this group of students, the relationship for the pair Geometry-Assembly is stronger than for those of the CAD role.

The correlation table for students taking no role is reported in table VIII. 
Table VIII Correlation table for No Role

\begin{tabular}{|c|c|c|c|c|c|c|c|c|c|c|c|}
\hline & 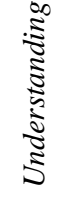 & 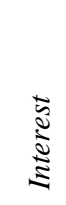 & 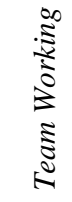 & 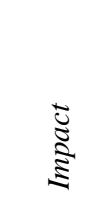 & 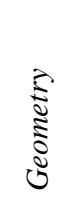 & 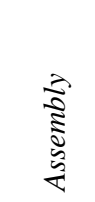 & 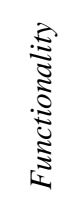 & $\begin{array}{l}\tilde{U} \\
\tilde{U} \\
\vdots \\
2\end{array}$ & $\begin{array}{c}\tilde{\Xi} \\
\stackrel{\Xi}{\Xi} \\
\stackrel{\Xi}{\Xi} \\
\mathbb{\Xi}\end{array}$ & 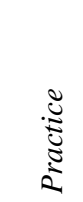 & 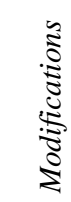 \\
\hline Motivation & .22 & .42 & .27 & .23 & .20 & .17 & .51 & .18 & .18 & .22 & .04 \\
\hline Understanding & & .49 & .49 & .18 & .20 & .20 & .25 & $.66 * *$ & $.69 * *$ & .33 & -.16 \\
\hline Interest & & & .53 & $.63 * *$ & .33 & .55 & .42 & .55 & $.65 * *$ & $.62 * *$ & -.15 \\
\hline Team Working & & & & .31 & .51 & $.59 * *$ & .47 & .40 & $.63 * *$ & .54 & -.17 \\
\hline Impact & & & & & .40 & .41 & .07 & .26 & .29 & .52 & .06 \\
\hline Geometry & & & & & & .45 & .53 & .16 & .48 & .42 & .15 \\
\hline Assembly & & & & & & & .47 & .15 & .38 & .56 & -.03 \\
\hline Functionality & & & & & & & & .25 & .44 & .32 & -.04 \\
\hline Process & & & & & & & & & .48 & .35 & -.29 \\
\hline Education & & & & & & & & & & .43 & -.28 \\
\hline Practice & & & & & & & & & & & .00 \\
\hline
\end{tabular}

** p-value $<0.01$

A moderate $(\tau>.60)$ to strong $(\tau>.80)$ linear association is statistically significant for the following pairs: Understanding-Process $(\tau=.66)$, Understanding-Education $(\tau=.69)$, Interest-Impact $(\tau=.63)$, InterestEducation $(\tau=.65)$, Interest-Practice $(\tau=.62)$, and Team Working-Education $(\tau=.63)$. The relationship between Interest and Practice was already discussed for the CAD role, whereas the one between Interest and Impact is also significant for the Manufacturing role. In both cases, the correlation of these pairs in table VIII is weaker than the one of the other roles, but a common background pattern is detected for the three roles. To conclude the analysis of the compulsory section, in order to provide a pilot profile of the feedback for the different roles, the average value of the level of agreement is considered for each role and aspect. The survey results can be summarized and represented by the radar map of Figure 4, although considering the mean is not correct from the point of view of statistics, because data are not continuous but ordinal, their distribution is not normal and the numerical values derive from qualitative levels. However, this summarizing operation does not contrast with the above psychometrics analyses that were carried out by non-parametric tests. An average value of 2.5 would indicate a neutral connotation of the feedback. Hence an average value below 2.5 is associated to a negative feedback, whereas a positive one is indicated by an average higher than 2.5. A darker background colour is used for a higher intensity of agreement or disagreement and the bold black line indicates the threshold of a neutral feedback. 
Figure 4 Summary by the average level of agreement for the twelve aspects - view by role
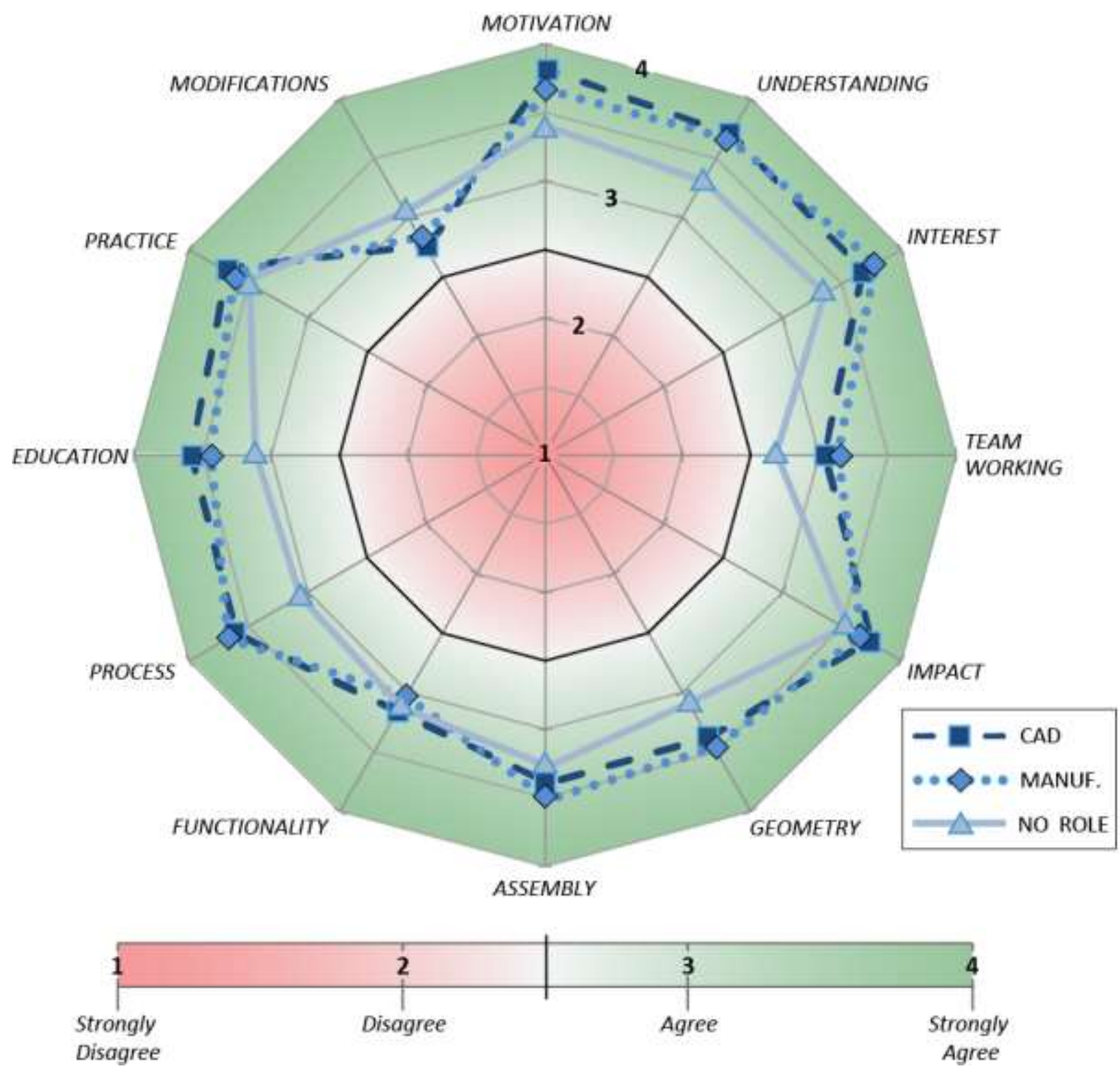

The continuous line refers to students having no specific role in the project. The profile of those who were mainly in charge of the CAD activity is represented by the dashed line, whereas the dotted line relates to the Manufacturing role. It is worth noticing that, with few exceptions, the three profiles run parallel to each other (Figure 4). In other words, the strength of agreement varies constantly for the three roles over all aspects. High similarity is observed between the CAD profile and the Manufacturing one, while greater differences are obtained for students that took no specific role in the project. This is consistent with the results about the median of the Kruskall-Wallis and Dunn tests that were presented afore for Motivation, Understanding, Interest and Process. Nevertheless, differences between profiles are minimal in the case of Impact, Assembly, Functionality and Practice. Hence, independently of their role, CAP students agree on the positive influence that the use of AM technologies in their engineering project has on those four aspects. Most of the aspects for which the No Role profile differentiates from the others are those composing the pairs with a significant moderate correlation in table VIII.

Once again, these considerations suggest that students taking no specific role report a lower agreement when compared to the other two roles due to the partial participation and involvement. This specific issue that arises a posteriori can be interpreted as a bias in the responses of the survey. Corrective measures are proposed in the conclusions to increase the students participation and involvement for the future, while improving team working skills. 
All the quotes provided by the students for the questions of the voluntary section are reported in the table A5 of the annexes and detailed by student's role. As expected, the number of feedbacks received for this section is inferior to the ones of the compulsory section and limited to less than 1/10 of the invited students. From 8 to 22 answers are collected for the five open questions, so a maximum of $1 / 4$ of the 81 responding students also completed the voluntary section partially. In accordance with the results of the compulsory section, the proportion of respondents that self-identified with the CAD role is also greater for the voluntary section. The low number of responses from students with no specific role can be ascribed once again to their scarce involvement in the CAP project. From these students, no response is recorded to voluntary questions about Usefulness (Q1) and Suggestions (Q5).

Responses are mainly but not exclusively related with topics that are closer to the self-identified role of the single student. Students with the CAD role principally refer to design activities, whereas students with the Manufacturing role mostly report issues of part fabrication or manufacturability. Students with no role provide answers related to either design or manufacturing.

For each of the five questions and aspects, the most frequent and significant answers are reported hereafter. As concerns the first question about Usefulness, most of the students state that the use of AM in the CAP practice was worthwhile to understand the potentialities of additive technologies in the near future together with the possibility to overtake the limits of traditional manufacturing.

"Understanding the principles of design for additive manufacturing in view of an increasing diffusion of these technologies"

"Broadening the mind by thinking of new opportunities of design of mechanical components overcoming the limits of conventional manufacturing technologies"

"Understanding the potentialities of additive manufacturing but also its shortcomings"

"Understanding new technologies that will change the way products will be fabricated in the future"

"Overcoming the design limits of traditional manufacturing technologies"

"Learning the potential of a manufacturing technology that I think will become very important in the near future"

Other responses highlight that the manufacturing of the physical product by FDM was useful for understanding better the functionality of the product with focus on movable parts, joints and clearances.

"Better understanding the geometry of the assembly and how the various parts can be redesigned in function of additive manufacturing"

"Understanding the geometry of the component and the mechanisms connecting moving parts"

"Understanding the functionality of the product. It was particularly useful to correctly design the moving parts of the assembly"

A few students express the usefulness in terms of the opportunity to fabricate complex assemblies as one piece through the reduction of the number of parts to be manufactured singularly.

"Getting an end-usable part by means of just one manufacturing operation”

"Fabricating an articulated assembly without many design limitations by just one manufacturing technology"

"Understanding how to simplify the design of a product, in particular reducing the total number of parts by incorporating them in a few $3 D$ printed assemblies"

A similar concept is also included among the answers to the second question about Advantages. As a matter of fact, most of the students reply to this question by declaring the advantage deriving from the product 
fabrication as one piece or a few parts, in short times by means of a single machine. A similar concept is expressed in terms of short assembling time deriving from the small number of parts to be assembled.

"Reducing the number of components in terms of lightweight design"

"The possibility of fabricating an integrated assembly by just one production step"

"Fabricating the final product in an easy way and in a relatively short time"

"The main benefit was found in the assembling phase, since the product was assembled from a few macroparts that were re-designed by applying the principles of design for additive manufacturing"

"Designing all the components of an assembly in an integrated way, saving time and costs while achieving a better quality for the single parts as well as for the whole product"

Another declared advantage is the possibility to study and design innovative technical solutions for joints and movable parts, when compared to traditional manufacturing techniques.

\footnotetext{
"The ability to create shapes and geometries which are impossible to fabricate by traditional injection moulding"
}

"Eliminating certain parts from the assembled product and replacing other through experiencing different technical solutions for the single pieces that once additive manufactured would ensure the correct operation and functionality"

"Overcoming those limitations in mechanical design that are commonly imposed by traditional manufacturing technologies”

The opportunity to see and touch the designed product is another obvious benefit reported by the students.

"It allows you to touch first-hand what would otherwise remain only on blueprints or as a 3D virtual model"

"First-hand experiencing additive manufacturing and its potential"

"Touching my project first-hand"

As regards Drawbacks, most of the feedbacks are related to the wrong clearance assigned for the correct kinematic of joints and movable parts. Too close tolerances were often assigned to mating parts, thus the designed mechanism had an incorrect motion and sometimes the removal of the support material was difficult.

\footnotetext{
"Dissolution of supporting material and structures was problematic because of small clearances between moving parts"
}

"Defining the clearance for the desired kinematic by considering the process tolerances of the AM machine for the large number of moving elements that were integrated in the assembly"

"Difficulties in the fabrication of moving parts because on the 3D model one does not realize how much clearance is assigning for the correct motion of the elements"

"Main difficulties in assigning the clearances to moving parts. The proper motion of the moving elements on the manufactured product was compromised by too tight clearances"

Some students admit the difficulties they encountered in thinking additive, that is in the redesign activity to adapt the product for the fabrication through AM.

"The need of a new design approach that takes into consideration the part having lower resistance because of the layer by layer manufacturing that is also a less accurate process" 
"The biggest challenge was to understand how to redesign the component for additive manufacturing, highlighting the differences compared to the original model"

"Difficulties in designing a component to be manufactured by a technology (FDM) that is unfortunately little treated in the other courses"

A few students report problems of the FDM machine, like the failure to supply the material to build support structures.

"Only once the AM machine failed in providing and depositing the support material, so the manufactured part was discarded"

Most of the issues and downsides reported by the students about machine failures or FDM process accuracy are well documented in the literature (Armillotta, 2006, Bakar et al., 2010, Bochmann et al., 2015, Boschetto and Bottini, 2014, Dimitrov et al., 2006, Johnson et al., 2014, Mahesh et al., 2004, Pei et al., 2011).

As concerns the fourth question about Changes, in order to solve the abovementioned problems related to the wrong clearances, students would modify the product geometry in terms of tolerances assigned to joints and integrated movable parts.

"I would increase the size of the gears to improve their meshing because their teeth on the manufactured part are too small"

"After looking at the additive manufacture parts, I would probably change clearances by reducing them in some areas and increasing them in others"

Several students would change the thickness to increase the resistance of their component.

"Honestly nothing, but at worst I would modify the locking system because it resulted too fragile during the assembling operation"

"I would increase the thickness of the levers for a greater resistance of the mechanism"

"The geometry and thickness of certain components in order to avoid breakage"

"The dimensions of the piece to make it more resistant to breakage"

A reference to this topic also recurs for the last aspect of Suggestions, wherein a better guidance during the redesign activity is recommended by the students. They also propose to integrate the project by including an economic evaluation and comparison about the costs of their product.

"To dedicate more time to the redesign activities by reporting some targeted examples"

"To include an economic analysis in the project"

"To provide more design guidelines and detailed examples and to include an analysis of production costs"

Finally they also would like to see other AM systems in operation, so they suggest adding other machines to the laboratory.

\footnotetext{
"To propose the experience again and possibly to show live also other techniques different from FDM"

"Add new AM machine to the laboratory"

"To use other AM technologies for the various teams to speed up the production, but also to allow for comparisons between different AM processes"
} 


\section{Case study}

This section is aimed at completing the overview of the educational framework in which the impact of additive manufacturing is assessed. To this purpose, one of the projects developed by the students during the CAP course is shortly presented in the following as a demonstration of the educational activity that directly affected the responses of the survey. Cost and performances of the FDM machine used for part manufacturing are also presented at the end of this section. For reasons of conciseness, only the selected case study is discussed as a best practice among the projects developed in the last three academic years. Less successful or less significant projects are not presented here, but their main limitations were associated with the lack of inventiveness in redesigning an existing product with new shapes or added value while adapting it for AM fabrication. In order to be fair, it should be remarked that the Master of Science program in Mechanical Engineering does not provide specific competences about industrial design. At the Department of Architecture and Design of the Politecnico di Torino there is a specific degree of Design and Visual Communication. Unlike engineers, industrial designers are educated to develop concepts for new products rich in cultural content, taking into account a complex series of requirements involving all the variables of the project. Not only technical but also humanistic concerns, such as cognitive ergonomics, psychology and visual communication are considered along with the essential requirements of environmental sustainability, comprehensibility and usability of the product in its form, its functions and its communicative value. The difference with respect to designers' education did not drive CAP students to fully exploit the potentialities of additive manufacturing in enhancing the value of the product from the industrial design perspective.

The selected case study from the students' projects refers to the additive manufacturing of a $1 / 10$ scale model of a downhill bike, whose overall dimensions are 408 x 196 x $257 \mathrm{~mm}$.

The scale model is divided into three parts to fit within the working volume of the FDM machines. The three parts are the front wheel structure, the frame and the rear wheel structure. Each part is manufactured as one piece, but it is composed of many elements that provide the proper functionality to the bike.

The front wheel structure includes the wheel, the tire, the disk brake, the fork with a shock absorber, the steering tube and a straight handlebar with the brake levers (Fig. 5a).

The frame structure includes the frame, the saddle, the pedals and the spring of the rear shock absorber (Fig. $5 b$ ). The head tube of the frame is cut to an appropriate amount to be easily assembled under a small pressure with the steering tube of the front wheel structure, allowing for the rotation of the handlebar. The pedals crank is integrated into the frame, while the crown for the transmission of the motion is replaced by a pulley. Because of the small size of the scale model, a rubber band is used instead of the chain, so also the pinion gears are replaced by another pulley on the rear wheel structure.

The rear wheel structure is constituted by the rear fork, the rear wheel, the rear braking system and the rod of the rear shock absorber (Fig. 5c). The rear fork is composed of a set of rods, suitably connected to form an articulated quadrilateral and the braking system includes a floating element similarly to the front brake. The rear wheel structure can be assembled with the frame by means of holes located at the free end of the quadrilatelar rods. These holes match four pins on the frame structure, while the rod of the rear shock absorber should be inserted into the coaxial spring.

Figure 5 The three parts of the $1 / 10$ scale model of the downhill bike

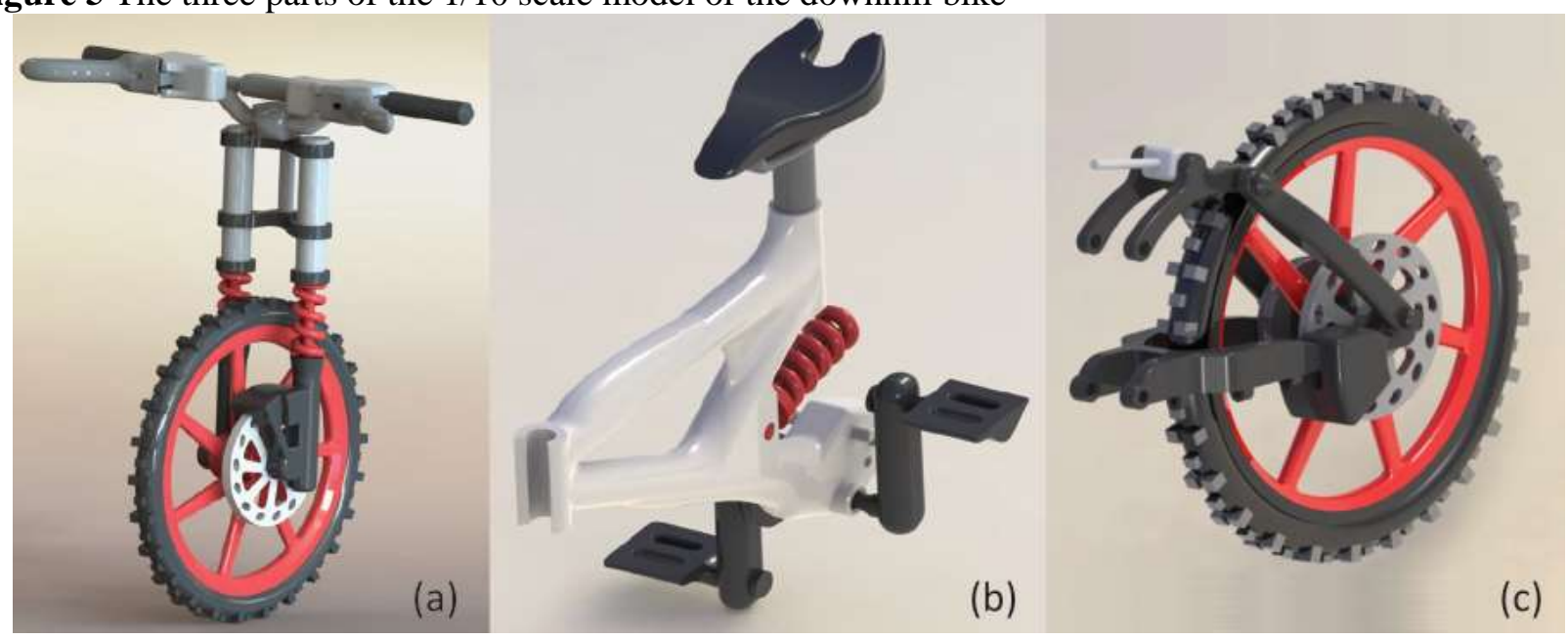


The front shock absorber of a downhill bike has a closed compact structure that makes it inaccessible to the introduction of foreign particles (gravel, mud, etc.) that may affect proper operation. In order to make the absorber functional also in the scale model, the spring being coaxial to the rod is moved to the outside of the tubular housing. Inside the housing, the end of the sliding rod is redesigned in such a way as to cause interference between the two bodies preventing the rod to come fully out of the sleeve (Fig. 6a). The brake levers can rotate around a pivot inside the handlebar to activate the braking system through a metal wire that is added after part manufacturing. The braking system (Fig. 6b) of the scale model is necessarily redesigned to account for the material, the small size of the elements and the limited workspace of pads. A flexible jaw is pushed against the disk by an appropriately shaped floating element that is connected to the brake lever by the metal wire. When the lever is pushed, the floating element moves up and exerts a force on the jaw that bends toward the disk. The return of the jaw is governed by the recovery of the elastic behaviour during bending and by gravity pushing the floating element downwards.

Figure 6 Cross section of the front shock absorber (a) and front breaking system (b)

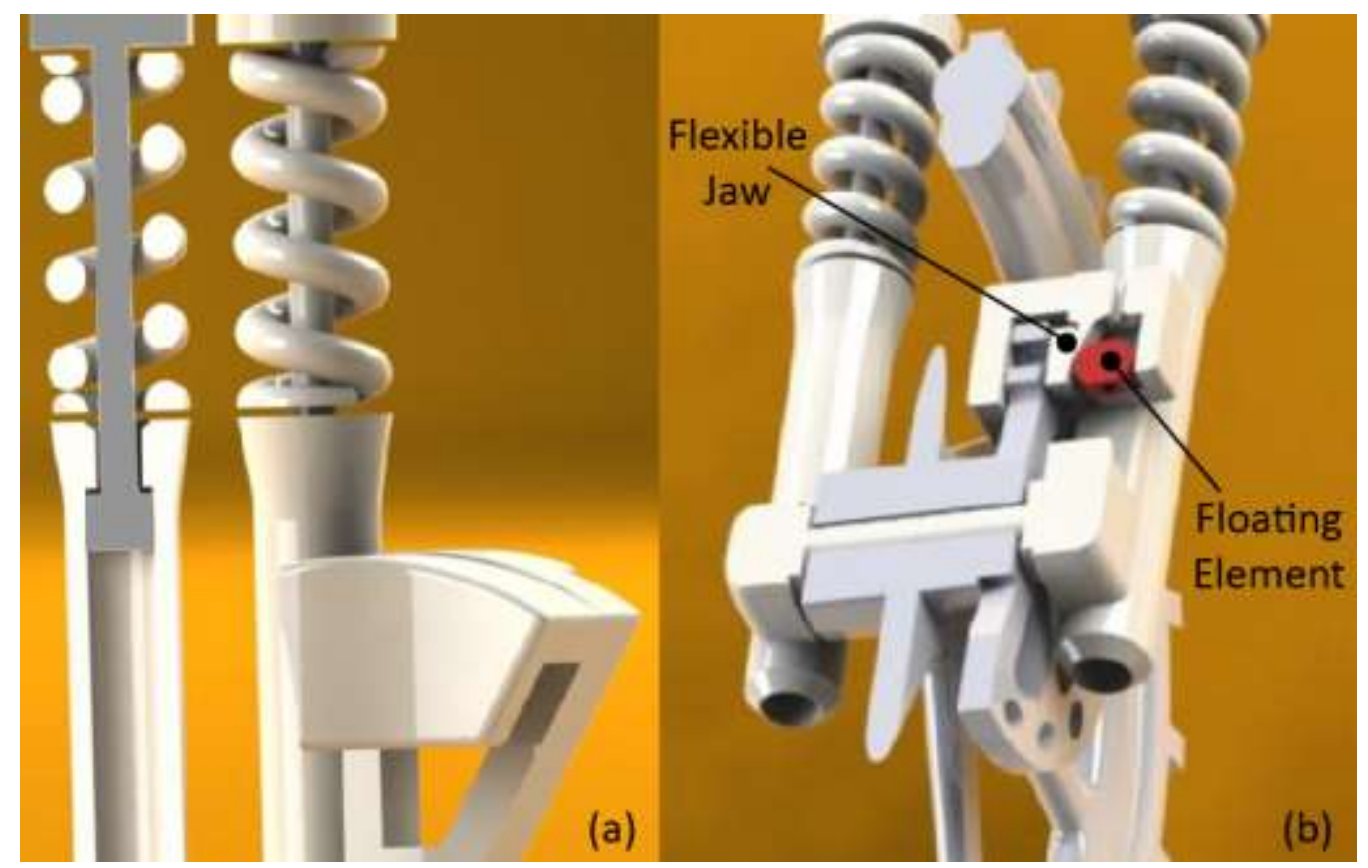

After manufacturing (Fig. 7) and assembling, parts are finished and painted. A metal wire is used to connect each brake lever to the corresponding floating element on the braking systems and the rubber band is mounted between the pulleys to perform the transmission (Fig. 8).

Figure 7 Rear wheel structure of ABS material with supports as fabricated

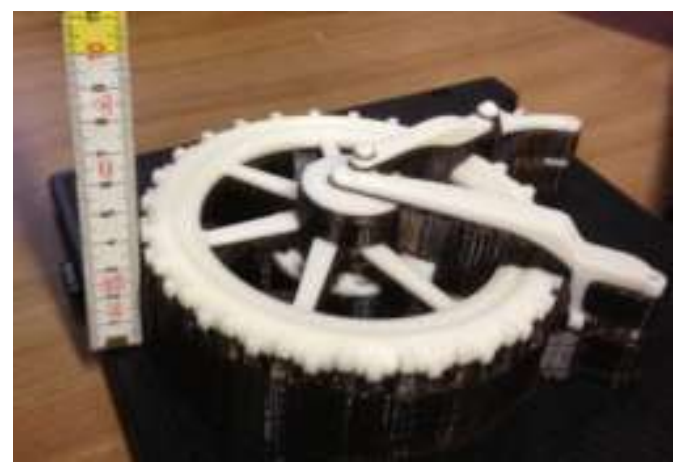

Figure 8 Detail of the transmission made by the two pulleys and rubber band 


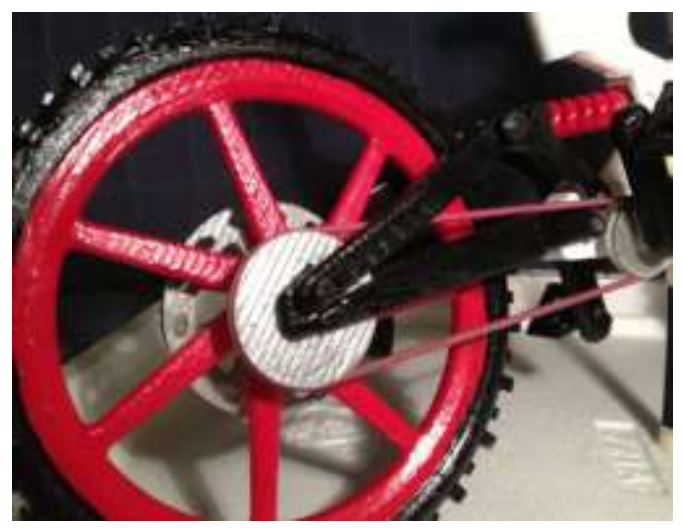

With reference to educational purposes, an indication of the AM costs for the downhill bike is provided in the following, considering both FDM machines that are available at the Rapid Manufacturing Laboratory. Starting from the cost model proposed by P. Alexander et al. (Alexander et al., 1998), a simplified cost model is used in this case. The total cost $\mathrm{C}_{\text {тот }}$ of each job of an FDM machine can be calculated as the sum of the material cost $\mathrm{C}_{\mathrm{MAT}}$ and the costs associated to the three phases of pre-processing $\mathrm{C}_{\mathrm{PRE}}$, building $\mathrm{C}_{\mathrm{BUILD}}$ and post-processing $\mathrm{C}_{\mathrm{POST}}$ :

$$
\mathrm{C}_{\mathrm{TOT}}=\mathrm{C}_{\mathrm{MAT}}+\mathrm{C}_{\mathrm{PRE}}+\mathrm{C}_{\mathrm{BUILD}}+\mathrm{C}_{\mathrm{POST}}
$$

For a comparison of costs between the Dimension Elite ${ }^{\mathrm{TM}}$ by Stratasys and 3D Touch ${ }^{\mathrm{TM}}$ by Bits from Bytes, the cost related to the pre-processing and the post-processing phases can be disregarded, because no significant difference is observed about the number of operations and the time required by the two machines. The material cost $\mathrm{C}_{\mathrm{MAT}}$ can be subdivided into the cost to build the part $\mathrm{C}_{\mathrm{PART}}$, plus the one required to build the support structures $\mathrm{C}_{\mathrm{SUPPORT}}$. These costs are a function of the volume of material or of material weight:

$$
\mathrm{C}_{\mathrm{MAT}}=\mathrm{C}_{\mathrm{PART}}+\mathrm{C}_{\mathrm{SUPPORT}}=\mathrm{C}_{\mathrm{V}, \text { PART }} \mathrm{V}_{\mathrm{PART}}+\mathrm{C}_{\mathrm{V}, \text { SUPPORT }} \mathrm{V}_{\text {SUPPORT }}
$$

Where $\mathrm{C}_{\mathrm{V} \text {, PART }}$ is the cost per unit volume or weight of the part material, $\mathrm{V}_{\text {PART }}$ is the volume or weight of the part, $\mathrm{C}_{\mathrm{V}}$, SUPPORT is the cost per unit volume or weight of the support material and $\mathrm{V}_{\text {SUPPORT }}$ is the volume or weight of the supports.

As regards the build cost, this is a function of building time $\mathrm{t}_{\mathrm{BUILD}}$ and of the machine hourly rate $\mathrm{C}_{\mathrm{MACH}}$ :

$$
\mathrm{C}_{\mathrm{BUILD}}=\mathrm{C}_{\mathrm{MACH}} \mathrm{t}_{\mathrm{BUILD}}
$$

Finally a corrective coefficient $\alpha_{\mathrm{EFF}}<1$ is included, to keep into account machine efficiency, that is quite different for the two machines according to the experience of the authors. The Dimension Elite ${ }^{\mathrm{TM}}$ machine is very reliable whereas the $3 \mathrm{D}$ Touch $^{\mathrm{TM}}$ exhibits some reliability issues related to its electronics. This machine often stops during the job without the possibility to recover it and to continue the part construction. In such undesired cases, the job has to be restarted and the deposited material is wasted.

By substitution of equations (2) and (3) in equation (1) and introduction of the machine efficiency, the final cost equation is:

$$
\mathrm{C}_{\text {TOT }}=\left(\mathrm{C}_{\mathrm{V}, \text { PART }} \mathrm{V}_{\text {PART }}+\mathrm{C}_{\mathrm{V} \text {, SUPPORT }} \mathrm{V}_{\mathrm{SUPPORT}}+\mathrm{C}_{\mathrm{MACH}} \mathrm{t}_{\mathrm{BUILD}}\right) / \alpha_{\mathrm{EFF}}
$$

For the front wheel structure, the frame and the rear wheel structure, the machine path, material volume or weight and build time are computed by means of Catalyst software in the case of Dimension Elite ${ }^{\mathrm{TM}}$ machine and Axon software in the case of 3D Touch ${ }^{\mathrm{TM}}$. Results are resumed in table IX. 
Table IX Amounts of material and building time for the three parts

\begin{tabular}{|c|c|c|c|c|c|c|}
\hline \multirow[b]{2}{*}{ Part } & \multicolumn{3}{|c|}{$\begin{array}{c}\text { Dimension Elite }{ }^{T M} \\
(\text { layer thickness }=0.178 \mathrm{~mm})\end{array}$} & \multicolumn{3}{|c|}{$\begin{array}{c}3 D \text { Touch } \\
\text { (layer thickness }=0.125 \mathrm{~mm})\end{array}$} \\
\hline & $V_{\text {PART }}$ & VSUPPORT & $\mathbf{t}_{\text {BUILD }}$ & VPART & V $_{\text {SUPPORT }}$ & $\mathbf{t}_{\text {BUILD }}$ \\
\hline Front wheel structure & $42 \mathrm{~cm}^{3}$ & $32 \mathrm{~cm}^{3}$ & $20 \mathrm{~h}$ & $423 \mathrm{gr}$ & $18 \mathrm{gr}$ & $175 \mathrm{~h}$ \\
\hline Frame & $101 \mathrm{~cm}^{3}$ & $155 \mathrm{~cm}^{3}$ & $57.5 \mathrm{~h}$ & $184 \mathrm{gr}$ & $8 \mathrm{gr}$ & $69 \mathrm{~h}$ \\
\hline Rear wheel structure & $70 \mathrm{~cm}^{3}$ & $90 \mathrm{~cm}^{3}$ & $29 \mathrm{~h}$ & $331 \mathrm{gr}$ & $14 \mathrm{gr}$ & $111 \mathrm{~h}$ \\
\hline
\end{tabular}

In terms of performances, the $3 \mathrm{D}$ Touch ${ }^{\mathrm{TM}}$ cannot heat multiple extruder heads at the same time, so there is an idle time in the construction of each layer if the machine should switch from the build material to the support material. This is the reason why times in table $\mathrm{X}$ are similar for the two machines in the case of the bike frame, although layer thickness is different for the two machines. For the other two parts, a lot of supporting structures are needed and thus building times for the 3D Touch ${ }^{\mathrm{TM}}$ are much longer.

The efficiency of Dimension Elite ${ }^{\mathrm{TM}}$ machine is assumed equal to .95 , that of $3 \mathrm{D}$ Touch $^{\mathrm{TM}}$ to .70 .

The machine hourly rate is computed starting from the investment cost and considering a depreciation over 5 years and 1600 working hours per year. The cost of the part material (ABS) and that of the support material is the same, so no distinction is made. The values in table IX are used to compute the total cost of the downhill bike whose terms are detailed in table X.

Table $\mathbf{X}$ Detailed comparison of cost terms for the downhill bike

\begin{tabular}{|c|c|c|c|c|}
\hline & & & Dimension Elite ${ }^{T M}$ & 3D Touch TM $^{T}$ \\
\hline Machine investment cost & (EUR) & - & 20,000 & 4,500 \\
\hline Depreciation period & (years) & - & 5 & 5 \\
\hline Yearly working hours & (hours) & - & 1600 & 1600 \\
\hline Machine hourly rate & (EUR/h) & $\mathrm{C}_{\text {Масн }}$ & 2.5 & 0.225 \\
\hline Machine efficiency & - & $\alpha_{\mathrm{EFF}}$ & 0.95 & 0.7 \\
\hline Material (ABS) cost per volume & $\left(\mathbf{E U R} / \mathbf{c m}^{3}\right)$ & CPART/SUPPORT & 0.27 & - \\
\hline Material (ABS) cost per weight & (EUR/gr) & CPART/Support & - & 0.06 \\
\hline \multirow{3}{*}{ Front wheel structure } & (EUR) & $\mathrm{C}_{\text {BUILD }}$ & 50 & 98 \\
\hline & (EUR) & $\mathrm{C}_{\mathrm{MAT}}$ & 20 & 27 \\
\hline & (EUR) & $\mathrm{C}_{\text {TOT }}$ & 74 & 178 \\
\hline \multirow{3}{*}{ Frame } & (EUR) & $\mathrm{C}_{\text {BUILD }}$ & 143 & 39 \\
\hline & (EUR) & $\mathrm{C}_{\mathrm{MAT}}$ & 69 & 12 \\
\hline & (EUR) & Стот & 224 & 72 \\
\hline \multirow{3}{*}{ Rear wheel structure } & (EUR) & $\mathrm{C}_{\text {BUILD }}$ & 72 & 62 \\
\hline & (EUR) & $\mathrm{C}_{\mathrm{MAT}}$ & 43 & 21 \\
\hline & (EUR) & Стот & 122 & 199 \\
\hline Downhill Bike & $(E U R)$ & TOTAL COST & 420 & 369 \\
\hline
\end{tabular}

In terms of part quality and part tolerances associated to part dimensions, from some first comparisons made on a common reference artefact, the accuracy of the Dimension Elite ${ }^{T M}$ is much better that that of $3 D$ Touch $^{T M}$ despite the thicker layer deposited $(0.178 \mathrm{~mm}$ vs. $0.125 \mathrm{~mm})$.

\section{Conclusions}

The relevance of direct access to AM technologies in a project-learning environment at academic level is attested by the direct feedback of mechanical engineering students to an administrated survey. Several aspects related to the group project developed within the CAP course are considered in the survey, by means of a positive statement for each of them. Students are asked to express their agreement or disagreement to the statements using a 4-point Likert scale. Owing to the affirmative connotation of the statements, a higher level of agreement by the students relates to positive influence of the use of AM in engineering educational activities.

In particular, unanimous consent is recorded as to the Impact that the use of AM has on learning the course topics. Highly positive feedbacks are also related to Motivation, Understanding, Interest and Education over other aspects. A lower agreement (still above 70\%) is obtained for the influence of AM use on Team 
Working skills. Within the working groups, few subjects report that they were not sufficiently involved or interested in the group project and state they took no active role in the activities. The statistical analysis of survey results shows that the responses of students with no specific role significantly differ from those of other students. Generally poor participation or interest relates to a less positive feedback than from the most committed students, which produces a biased perception of the benefits of AM use. On the other hand, AM use has low influence on improving team working skills that are not exclusive of the engineering field, but generally related to people management.

A first action to improve team working could be to introduce the attendance tracking. Such measure will increase participation, but not students' interest in the project. Commonly, team working is affected by involvement and commitment. New roles may be introduced to improve these two aspect for an active participation of students. Along with the $\mathrm{CAD}$ designer and the manufacturing role, those of team manager, photographer and communication manager can be assigned to other students inside the group. The attribution of responsibility could make people feel personally involved. These corrective actions are not expected to improve the impact of AM on team working, but at least they should reduce the bias observed for the received feedbacks.

The lowest student appreciation is obtained for the function of AM in suggesting modifications to the original design, on which $35 \%$ of the respondents totally disagreed.

The weaker consensus on this last aspect can be better understood in the light of two boundary conditions, due to project schedule. First, the re-design activity is not pushed to the limit and no topology optimisation is implemented in the FE analysis. Second, peculiar strengths of AM such as conformal cooling channels in the mold are disregarded. Both limitations hamper full exploitation of AM potentialities.

On a more general level, several voluntary answers to the open questions of the survey report that the AM adoption in the CAP course project helps students to hands-on detect and verify design errors, especially in the case of clearance in complex assemblies with several moving parts. In a "learn by doing" educational environment, the possibility to see AM technologies in operation contributes to shape the engineering sensitivity of students towards current developing and diffusing manufacturing technologies.

In summary, this work assesses that entry-level AM devices can be a successful tool in the formation of engineers, who can benefit from a hands-on experience and acquire capabilities both on engineering design skills and on new manufacturing technologies that are being referred to as the third industrial revolution. The education to AM at all levels assumes paramount importance, because a learn-by-doing environment promotes innovation and creativity, allowing students to experience the model stage of the design process while improving their problem solving skills (Lacey, 2010).

A democratized use of entry-level AM machines will impose the need for educating people to advanced 3D modelling by using professional CAD software packages or even open freeware packages with enhanced modelling functions. Design and modelling skills will empower people to fabricate self-designed spare parts at home. Self-made fixing of broken products will extend products' lifecycle and durability, while contributing to restrain rampant consumerism. This great potential to influence civilization lays its foundation on the education of people to the use of additive techniques. 


\section{References}

Alexander, P., Allen, S.and Dutta, D. (1998), "Part orientation and build cost determination in layered manufacturing", Computer-Aided Design, Vol. 30 Nr. 5, pp. 343-356.

Armillotta, A. (2006), "Assessment of surface quality on textured FDM prototypes", Rapid Prototyping Journal, Vol. 12 Nr. 1, pp. 35-41.

Atzeni, E., Iuliano, L., Minetola, P.and Salmi, A. (2010a), "Redesign and cost estimation of rapid manufactured plastic parts", Rapid Prototyping Journal, Vol. 16 Nr. 5, pp. 308-317.

Atzeni, E., Iuliano, L., Minetola, P., Salmi, A.and Gatto, A. (2010b), "A benchmark for accuracy evaluation of dental crowns up-to-date manufacturing", Innovative Developments in Design and Manufacturing, Vol. Nr. pp. 425-430.

Aw, K. C., Xie, S. Q.and Haemmerle, E. (2007), "A FPGA-based rapid prototyping approach for teaching of Mechatronics Engineering", Mechatronics, Vol. 17 Nr. 8, pp. 457-461.

Bakar, N., Alkahari, M.and Boejang, H. (2010), "Analysis on fused deposition modelling performance", Journal of Zhejiang University SCIENCE A, Vol. 11 Nr. 12, pp. 972-977.

Bassoli, E., Gatto, A.and Iuliano, L. (2012), "Joining mechanisms and mechanical properties of PA composites obtained by selective laser sintering", Rapid Prototyping Journal, Vol. 18 Nr. 2, pp. 100-108.

Bassoli, E., Gatto, A., Iuliano, L.and Violante, M. G. (2007), "3D printing technique applied to rapid casting", Rapid Prototyping Journal, Vol. 13 Nr. 3, pp. 148-155.

Becker, R., Grzesiak, A.and Henning, A. (2005), "Rethink assembly design", Assembly Automation, Vol. 25 Nr. 4, pp. 262-266.

Berti, G., D'angelo, L., Gatto, A.and Iuliano, L. (2010), "Mechanical characterisation of PA-A12O3 composites obtained by selective laser sintering", Rapid Prototyping Journal, Vol. 16 Nr. 2, pp. 124-129.

Bidanda, B., Arisoy, O.and Shumah, L. J. (2006), "Offshoring manufacturing: Implications for engineering jobs and education: A survey and case study", Robotics and ComputerIntegrated Manufacturing, Vol. 22 Nr. 5-6, pp. 576-587.

Bochmann, L., Bayley, C., Helu, M. T., Transchel, R., Wegener, K.and Dornfeld, D. (2015), "Understanding error generation in fused deposition modeling", Surface Topography: Metrology and Properties, Vol. 3 Nr. 1, pp. 014002.

Boschetto, A.and Bottini, L. (2014), "Accuracy prediction in fused deposition modeling", International Journal of Advanced Manufacturing Technology, Vol. 73 Nr. 5-8, pp. 913 928.

Buehler, E., Kane, S. K.and Hurst, A. 2014. ABC and 3D: opportunities and obstacles to 3D printing in special education environments. Proceedings of the 16th international ACM SIGACCESS conference on Computers \& accessibility. Rochester, New York, USA: ACM.

Calignano, F., Manfredi, D., Ambrosio, E. P., Iuliano, L.and Fino, P. (2013), "Influence of process parameters on surface roughness of aluminum parts produced by DMLS", International Journal of Advanced Manufacturing Technology, Vol. 67 Nr. 9-12, pp. 2743-2751.

Dimitrov, D., Van Wijck, W., Schreve, K.and De Beer, N. (2006), "Investigating the achievable accuracy of three dimensional printing", Rapid Prototyping Journal, Vol. 12 Nr. 1, pp. $42-$ 52.

Drake, R. L.and Pawlina, W. (2014), "An Addition to the Neighborhood: 3D Printed Anatomy Teaching Resources", Anatomical Sciences Education, Vol. 7 Nr. 6, pp. 419-419.

Eisenberg, M. (2013), "3D printing for children: What to build next?", International Journal of Child-Computer Interaction, Vol. 1 Nr. 1, pp. 7-13.

Gatto, A., Iuliano, L., Calignano, F.and Bassoli, E. (2012), "Electrodischarge drilling performance on parts produced by DMLS", International Journal of Advanced Manufacturing Technology, Vol. 58 Nr. 9-12, pp. 1003-1018. 
Gibson, I., Rosen, D. W.and Stucker, B. 2010. Design for Additive Manufacturing. Additive Manufacturing Technologies: Rapid Prototyping to Direct Digital Manufacturing. Springer US.

Hague, R., Campbell, I.and Dickens, P. (2003a), "Implications on design of rapid manufacturing", Proceedings of the Institution of Mechanical Engineers Part C-Journal of Mechanical Engineering Science, Vol. 217 Nr. 1, pp. 25-30.

Hague, R., Mansour, S.and Saleh, N. (2003b), "Design opportunities with rapid manufacturing", Assembly Automation, Vol. 23 Nr. 4, pp. 346-356.

Huang, S. H., Liu, P., Mokasdar, A.and Hou, L. (2013), "Additive manufacturing and its societal impact: a literature review", International Journal of Advanced Manufacturing Technology, Vol. 67 Nr. 5-8, pp. 1191-1203.

Johnson, W. M., Rowell, M., Deason, B.and Eubanks, M. (2014), "Comparative evaluation of an open-source FDM system", Rapid Prototyping Journal, Vol. 20 Nr. 3, pp. 205-214.

Khajavi, S. H., Partanen, J.and Holmstrom, J. (2014), "Additive manufacturing in the spare parts supply chain", Computers in Industry, Vol. 65 Nr. 1, pp. 50-63.

Kostakis, V., Niaros, V.and Giotitsas, C. (2015), "Open source 3D printing as a means of learning: An educational experiment in two high schools in Greece", Telematics and Informatics, Vol. 32 Nr. 1, pp. 118-128.

Lacey, G. (2010), "3D Printing Brings Designs to Life", Tech Directions, Vol. 70 Nr. 2, pp. 17-19.

Le Bourhis, F., Kerbrat, O., Hascoet, J. Y.and Mognol, P. (2013), "Sustainable manufacturing: evaluation and modeling of environmental impacts in additive manufacturing", International Journal of Advanced Manufacturing Technology, Vol. 69 Nr. 9-12, pp. 1927-1939.

Mahesh, M., Wong, Y., Fuh, J. Y. H.and Loh, H. T. (2004), "Benchmarking for comparative evaluation of RP systems and processes", Rapid Prototyping Journal, Vol. 10 Nr. 2, pp. 123-135.

Manfredi, D., Calignano, F., Ambrosio, E. P., Krishnan, M., Canali, R., Biamino, S., Pavese, M., Atzeni, E., Iuliano, L., Fino, P.and Badini, C. (2013), "Direct Metal Laser Sintering: an additive manufacturing technology ready to produce lightweight structural parts for robotic applications", Metallurgia Italiana, Vol. Nr. 10, pp. 15-24.

Mills, J. E.and Treagust, D. F. (2003), "Engineering education-Is problem-based or project-based learning the answer?", Australasian Journal of Engineering Education, Vol. 3 Nr. 1, pp. 216.

Minetola, P.and Iuliano, L. (2012), "Investigation of wear behaviour of FDM fixtures", Innovative Developments on Virtual and Physical Prototyping, Vol. Nr. pp. 749-756.

Minetola, P.and Iuliano, L. (2014), "The reverse guillotine tribometer for evaluation of sliding wear of additive manufactured fixtures", Rapid Prototyping Journal, Vol. 20 Nr. 2, pp. 105-114.

Moret, L., Mesbah, M., Chwalow, J.and Lellouch, J. (1993), "Internal Validation of a Scale Relationship between Principal Component Analysis - Cronbach Alpha and Reliability", Revue D Epidemiologie Et De Sante Publique, Vol. 41 Nr. 2, pp. 179-186.

Oxford, R. (1997), "Cooperative learning, collaborative learning and interaction: three communicative strands in the language classroom", Modern Language Journal, Vol. $81 \mathrm{Nr}$. 1, pp. 443-456.

Pei, E. J., Campbell, R. I.and De Beer, D. (2011), "Entry-level RP machines: how well can they cope with geometric complexity?", Assembly Automation, Vol. 31 Nr. 2, pp. 153-160.

The Economist. 2012. Manufacturing: The third Industrial Revolution. The Economist Special Report "The Third Industrial Revolution", April 21st 2012.

Violante, M. G., Iuliano, L.and Minetola, P. (2007), "Design and production of fixtures for freeform components using selective laser sintering", Rapid Prototyping Journal, Vol. 13 Nr. 1, pp. 30-37. 
Wittbrodt, B. T., Glover, A. G., Laureto, J., Anzalone, G. C., Oppliger, D., Irwin, J. L.and Pearce, J. M. (2013), "Life-cycle economic analysis of distributed manufacturing with open-source 3D printers", Mechatronics, Vol. 23 Nr. 6, pp. 713-726.

Wong, D. S. K., Zaw, H. M.and Tao, Z. J. (2014), "Additive manufacturing teaching factory: driving applied learning to industry solutions", Virtual and Physical Prototyping, Vol. 9 Nr. 4, pp. 205-212.

Zhang, C. L., Anzalone, N. C., Faria, R. P.and Pearce, J. M. (2013), "Open-Source 3D-Printable Optics Equipment", Plos One, Vol. 8 Nr. 3, pp. 1-13. 


\section{Annexes}

Table A1 Detailed feedback received for the compulsory section with percentages for each item and role in parenthesis

\begin{tabular}{|c|c|c|c|c|c|c|c|c|c|}
\hline \multirow{2}{*}{ Aspect } & \multirow{2}{*}{ Feedback } & \multicolumn{6}{|c|}{ Student's role } & \multirow{2}{*}{\multicolumn{2}{|c|}{ Total }} \\
\hline & & \multicolumn{2}{|c|}{ CAD } & \multicolumn{2}{|c|}{ MANUFACT. } & \multicolumn{2}{|c|}{ NO ROLE } & & \\
\hline \multirow{2}{*}{ Motivation } & Strongly agree & 38 & $(86.3 \%)$ & 12 & $(70.6 \%)$ & 11 & $(52.4 \%)$ & 61 & $(74.4 \%)$ \\
\hline & Agree & 4 & $(9.1 \%)$ & 4 & $(23.5 \%)$ & 7 & $(33.3 \%)$ & 15 & $(18.3 \%)$ \\
\hline \multirow{2}{*}{$\begin{array}{l}\text { The fabrication of designed parts increased } \\
\text { your learning motivation }\end{array}$} & Disagree & 1 & $(2.3 \%)$ & 1 & $(5.9 \%)$ & 3 & $(14.3 \%)$ & 5 & $(6.1 \%)$ \\
\hline & Strongly disagree & 1 & $(2.3 \%)$ & 0 & $(0 \%)$ & 0 & $(0 \%)$ & 1 & $(1.2 \%)$ \\
\hline \multirow{2}{*}{ Understanding } & Strongly agree & 31 & $(70.5 \%)$ & 11 & $(64.7 \%)$ & 6 & $(28.6 \%)$ & 48 & $(58.6 \%)$ \\
\hline & Agree & 12 & $(27.3 \%)$ & 6 & $(35.3 \%)$ & 15 & $(71.4 \%)$ & 33 & $(40.2 \%)$ \\
\hline \multirow{2}{*}{$\begin{array}{l}\text { The project was helpful in understanding } \\
\text { the course topics }\end{array}$} & Disagree & 1 & $(2.3 \%)$ & 0 & $(0 \%)$ & 0 & $(0 \%)$ & 1 & $(1.2 \%)$ \\
\hline & Strongly disagree & 0 & $(0 \%)$ & 0 & $(0 \%)$ & 0 & $(0 \%)$ & $\mathbf{0}$ & $(0 \%)$ \\
\hline \multirow{4}{*}{$\begin{array}{l}\text { Interest } \\
\text { The project increased your interest in the } \\
\text { course topics }\end{array}$} & Strongly agree & 33 & $(75 \%)$ & 13 & $(76.5 \%)$ & 9 & $(42.9 \%)$ & 55 & $(67.1 \%)$ \\
\hline & Agree & 8 & $(18.2 \%)$ & 4 & $(23.5 \%)$ & 10 & $(47.6 \%)$ & 22 & $(26.8 \%)$ \\
\hline & Disagree & 2 & $(4.5 \%)$ & 0 & $(0 \%)$ & 2 & $(9.5 \%)$ & 4 & $(4.9 \%)$ \\
\hline & Strongly disagree & 1 & $(2.3 \%)$ & 0 & $(0 \%)$ & 0 & $(0 \%)$ & 1 & $(1.2 \%)$ \\
\hline \multirow{4}{*}{$\begin{array}{l}\text { Team Working } \\
\text { The use of AM systems improved your } \\
\text { team working skills }\end{array}$} & Strongly agree & 12 & $(27.3 \%)$ & 6 & $(35.3 \%)$ & 1 & $(4.8 \%)$ & 19 & $(23.2 \%)$ \\
\hline & Agree & 22 & $(50 \%)$ & 7 & $(41.2 \%)$ & 13 & $(61.9 \%)$ & 42 & $(51.2 \%)$ \\
\hline & Disagree & 9 & $(20.5 \%)$ & 4 & $(23.5 \%)$ & 6 & $(28.6 \%)$ & 19 & $(23.2 \%)$ \\
\hline & Strongly disagree & 1 & $(2.3 \%)$ & 0 & $(0 \%)$ & 1 & $(4.8 \%)$ & 2 & $(2.4 \%)$ \\
\hline \multirow{2}{*}{ Impact } & Strongly agree & 32 & $(72.7 \%)$ & 11 & $(64.7 \%)$ & 11 & $(52.4 \%)$ & 54 & $(65.9 \%)$ \\
\hline & Agree & 12 & $(27.3 \%)$ & 6 & $(35.3 \%)$ & 10 & $(47.6 \%)$ & 28 & $(34.1 \%)$ \\
\hline \multirow{2}{*}{$\begin{array}{l}\text { You think you learnt more than if you only } \\
\text { studied theory }\end{array}$} & Disagree & 0 & $(0 \%)$ & 0 & $(0 \%)$ & 0 & $(0 \%)$ & $\mathbf{0}$ & $(0 \%)$ \\
\hline & Strongly disagree & 0 & $(0 \%)$ & 0 & $(0 \%)$ & 0 & $(0 \%)$ & $\mathbf{0}$ & $(0 \%)$ \\
\hline \multirow{4}{*}{$\begin{array}{l}\text { Geometry } \\
\text { You gained a better understanding of the } \\
\text { geometry of parts }\end{array}$} & Strongly agree & 24 & $(54.5 \%)$ & 8 & $(47.1 \%)$ & 6 & $(28.6 \%)$ & 38 & $(46.3 \%)$ \\
\hline & Agree & 13 & $(29.5 \%)$ & 9 & $(52.9 \%)$ & 11 & $(52.4 \%)$ & 33 & $(40.2 \%)$ \\
\hline & Disagree & 7 & $(15.9 \%)$ & 0 & $(0 \%)$ & 4 & $(19 \%)$ & 11 & $(13.4 \%)$ \\
\hline & Strongly disagree & 0 & $(0 \%)$ & 0 & $(0 \%)$ & 0 & $(0 \%)$ & $\mathbf{0}$ & $(0 \%)$ \\
\hline \multirow{2}{*}{ Assembly } & Strongly agree & 25 & $(56.8 \%)$ & 10 & $(58.8 \%)$ & 8 & $(38.1 \%)$ & 43 & $(52.4 \%)$ \\
\hline & Agree & 13 & $(29.5 \%)$ & 6 & $(35.3 \%)$ & 11 & $(52.4 \%)$ & 30 & $(36.6 \%)$ \\
\hline \multirow{2}{*}{$\begin{array}{l}\text { You better understood how the single parts } \\
\text { assemble into the whole product }\end{array}$} & Disagree & 5 & $(11.4 \%)$ & 1 & $(5.9 \%)$ & 2 & $(9.5 \%)$ & 8 & $(9.8 \%)$ \\
\hline & Strongly disagree & 1 & $(2.3 \%)$ & 0 & $(0 \%)$ & 0 & $(0 \%)$ & 1 & $(1.2 \%)$ \\
\hline \multirow{4}{*}{$\begin{array}{l}\text { Functionality } \\
\text { You gained a better understanding of the } \\
\text { functionality of the whole product }\end{array}$} & Strongly agree & 19 & $(43.2 \%)$ & 5 & $(29.4 \%)$ & 4 & $(19 \%)$ & 28 & $(34.1 \%)$ \\
\hline & Agree & 16 & $(36.4 \%)$ & 8 & $(47.1 \%)$ & 16 & $(76.2 \%)$ & 40 & $(48.8 \%)$ \\
\hline & Disagree & 7 & $(15.9 \%)$ & 4 & $(23.5 \%)$ & 1 & $(4.8 \%)$ & 12 & $(14.6 \%)$ \\
\hline & Strongly disagree & 2 & $(4.5 \%)$ & 0 & $(0 \%)$ & 0 & $(0 \%)$ & 2 & $(2.4 \%)$ \\
\hline & Strongly agree & 29 & $(65.9 \%)$ & 12 & $(70.6 \%)$ & 6 & $(28.6 \%)$ & 47 & $(57.3 \%)$ \\
\hline The direct use of the AM machine & Agree & 14 & $(31.8 \%)$ & 5 & $(29.4 \%)$ & 11 & $(52.4 \%)$ & 30 & $(36.6 \%)$ \\
\hline increased your understanding of the & Disagree & 1 & $(2.3 \%)$ & 0 & $(0 \%)$ & 4 & $(19 \%)$ & 5 & $(6.1 \%)$ \\
\hline & Strongly disagree & 0 & $(0 \%)$ & 0 & $(0 \%)$ & 0 & $(0 \%)$ & $\mathbf{0}$ & $(0 \%)$ \\
\hline Education & Strongly agree & 28 & $(63.6 \%)$ & 9 & $(52.9 \%)$ & 8 & $(38.1 \%)$ & 45 & $(54.9 \%)$ \\
\hline The knowledge and skills obtained thanks & Agree & 15 & $(34.1 \%)$ & 7 & $(41.2 \%)$ & 8 & $(38.1 \%)$ & 30 & $(36.6 \%)$ \\
\hline to the project are relevant to your & Disagree & 1 & $(2.3 \%)$ & 1 & $(5.9 \%)$ & 5 & $(23.8 \%)$ & 7 & $(8.5 \%)$ \\
\hline educational objectives & Strongly disagree & 0 & $(0 \%)$ & 0 & $(0 \%)$ & 0 & $(0 \%)$ & $\mathbf{0}$ & $(0 \%)$ \\
\hline Lab Practice & Strongly agree & 33 & $(75 \%)$ & 12 & $(70.6 \%)$ & 12 & $(57.1 \%)$ & 57 & $(69.5 \%)$ \\
\hline You would recommend the adoption of & Agree & 9 & $(20.5 \%)$ & 4 & $(23.5 \%)$ & 8 & $(38.1 \%)$ & 21 & $(25.6 \%)$ \\
\hline $\mathrm{AM}$ as a common tool for lab practice in & Disagree & 2 & $(4.5 \%)$ & 1 & $(5.9 \%)$ & 1 & $(4.8 \%)$ & 4 & $(4.9 \%)$ \\
\hline manufacturing technology courses & Strongly disagree & 0 & $(0 \%)$ & 0 & $(0 \%)$ & 0 & $(0 \%)$ & $\mathbf{0}$ & $(0 \%)$ \\
\hline Modifications & Strongly agree & 7 & $(15.9 \%)$ & 5 & $(29.4 \%)$ & 8 & $(38.1 \%)$ & 20 & $(24.4 \%)$ \\
\hline If you had to design the part again after & Agree & 22 & $(50 \%)$ & 5 & $(29.4 \%)$ & 6 & $(28.6 \%)$ & 33 & $(40.2 \%)$ \\
\hline you got the additive manufactured parts, & Disagree & 12 & $(27.3 \%)$ & 6 & $(35.3 \%)$ & 7 & $(33.3 \%)$ & 25 & $(30.5 \%)$ \\
\hline dimensions or tolerances & Strongly disagree & 3 & $(6.8 \%)$ & 1 & $(5.9 \%)$ & 0 & $(0 \%)$ & 4 & $(4.9 \%)$ \\
\hline
\end{tabular}


Table A2 Descriptive statistics for the CAD role

\begin{tabular}{lcccc}
\hline Aspect & Median & $\begin{array}{c}\text { Median } \\
\text { Absolute } \\
\text { Deviation }\end{array}$ & Skewness & Kurtosis \\
\hline Motivation & 4 & 0 & -3.18 & 10.37 \\
Understanding & 4 & 0 & -1.24 & 0.44 \\
Interest & 4 & 0 & -2.09 & 4.13 \\
Team Working & 3 & 0.74 & -0.34 & -0.47 \\
Impact & 4 & 0 & -0.99 & -1.05 \\
Geometry & 4 & 0 & -0.74 & -0.92 \\
Assembly & 4 & 0 & -1.10 & 0.36 \\
Functionality & 3 & 1.48 & -0.76 & -0.32 \\
Process & 4 & 0 & -0.99 & -0.18 \\
Education & 4 & 0 & -0.88 & -0.41 \\
Practice & 4 & 0 & -1.64 & 1.70 \\
Modifications & 3 & 0.74 & -0.3 & -0.41 \\
\hline
\end{tabular}

Table A3 Descriptive statistics for the Manufacturing role

\begin{tabular}{lcccc}
\hline Aspect & Median & $\begin{array}{c}\text { Median } \\
\text { Absolute } \\
\text { Deviation }\end{array}$ & Skewness & Kurtosis \\
\hline Motivation & 4 & 0 & -1.33 & 0.59 \\
Understanding & 4 & 0 & -0.56 & -1.78 \\
Interest & 4 & 0 & -1.14 & -0.73 \\
Team Working & 3 & 1.48 & -0.18 & -1.44 \\
Impact & 4 & 0 & -0.56 & -1.78 \\
Geometry & 3 & 0 & 0.11 & -2.10 \\
Assembly & 4 & 0 & -0.83 & -0.51 \\
Functionality & 3 & 1.48 & -0.08 & -1.31 \\
Process & 4 & 0 & -0.83 & -1.39 \\
Education & 4 & 0 & -0.62 & -0.78 \\
Practice & 4 & 0 & -1.33 & 0.59 \\
Modifications & 3 & 1.48 & -0.09 & -1.32 \\
\hline
\end{tabular}

Table A4 Descriptive statistics for No Role

\begin{tabular}{lcccc}
\hline Aspect & Median & $\begin{array}{c}\text { Median } \\
\text { Absolute } \\
\text { Deviation }\end{array}$ & Skewness & Kurtosis \\
\hline Motivation & 4 & 0 & -0.67 & -0.99 \\
Understanding & 3 & 0 & 0.88 & -1.28 \\
Interest & 3 & 1.48 & -0.41 & -0.91 \\
Team Working & 3 & 0 & -0.59 & 0.10 \\
Impact & 4 & 0 & -0.09 & -2.08 \\
Geometry & 3 & 0 & -0.11 & -1.06 \\
Assembly & 3 & 0 & -0.28 & -0.89 \\
Functionality & 3 & 0 & 0.43 & 0.53 \\
Process & 3 & 0 & -0.11 & -1.06 \\
Education & 3 & 1.48 & -0.23 & -1.45 \\
Practice & 4 & 0 & -0.74 & -0.6 \\
Modifications & 3 & 1.48 & -0.08 & -1.72 \\
\hline
\end{tabular}


Table A5 Summary of key students reflections for the voluntary section

\section{Q1 - Usefulness}

Think about what you have learnt through developing the project. What was the access to additive manufacturing useful for?

Responses from students that self-identified with the CAD role

- Getting an end-usable part by means of just one manufacturing operation

- Understanding the principles of design for additive manufacturing in view of an increasing diffusion of these technologies

- Fabricating an articulated assembly without many design limitations by just one manufacturing technology

- Broadening the mind by thinking of new opportunities of design of mechanical components overcoming the limits of conventional manufacturing technologies

- Understanding the potentialities of additive manufacturing but also its shortcomings

- $\quad$ Touching with hands the concepts that are usually only studied in theory. This allowed me to really understand the potential of these technologies and the difficulties in designing a single component with articulated parts

- Understanding how to fabricate a complex part without using traditional techniques (injection moulding for plastics)

- Understanding how the FDM process works

- Understanding how to simplify the design of a product, in particular reducing the total number of parts by incorporating them in a few 3D printed assemblies

- Understanding new technologies that will change the way products will be fabricated in the future

- Considering some design issues that probably would otherwise have been disregarded

- Better understanding the geometry of the assembly and how the various parts can be redesigned in function of additive manufacturing

- Overcoming the design limits of traditional manufacturing technologies

Responses from students that self-identified with the Manufacturing role

- Understanding the difficulties of correctly designing mechanical assemblies

- Learning the potential of a manufacturing technology that I think will become very important in the near future

- Understanding the geometry of the component and the mechanisms connecting moving parts

- Understanding the functionality of the product. It was particularly useful to correctly design the moving parts of the assembly

\section{Q2 - Advantages}

What were the advantages of realizing a project that integrates mechanical design of assemblies with their fabrication by additive technologies?

Responses from students that self-identified with the CAD role

- Fabricating assemblies as one piece with a single operation

- Touching my project first-hand

- Designing all the components of an assembly in an integrated way, saving time and costs while achieving a better quality for the single parts as well as for the whole product

- Designing with a comprehensive approach by considering that a complex assembly will be fabricated as a single piece

- Eliminating certain parts from the assembled product and replacing other through experiencing different technical solutions for the single pieces that once additive manufactured would ensure the correct operation and functionality

- Better understanding and hands-on experience of what is commonly only studied in theory

- The main benefit was found in the assembling phase, since the product was assembled from a few macro-parts that were re-designed by applying the principles of design for additive manufacturing

- Detecting and verifying functional problems along with the reduction of times required to fabricate a product sample

- The possibility to identify design errors by comparing the additive manufactured piece with its CAD model 
- The main advantage is that one can fabricate a full working mock-up at low cost to analyse the geometry of the parts

- Understanding how the production process can be considerably reduced in terms of time

- Overcoming those limitations in mechanical design that are commonly imposed by traditional manufacturing technologies

- It helps understanding that while designing a product, the fabrication process is an important factor to be considered

Responses from students that self-identified with the Manufacturing role

- $\quad$ Reducing the number of components in terms of lightweight design

- It allows you to touch first-hand what would otherwise remain only on blueprints or as a 3D virtual model

- The ability to create shapes and geometries which are impossible to fabricate by traditional injection moulding

- The possibility of fabricating an integrated assembly by just one production step

- Understanding that besides manufacturing innovation of additive technologies is also affecting the design activities

- $\quad$ Touching the project first-hand

Responses from students that self-identified without a specific role

- $\quad$ Thinking deeply on the actual functionality of the components

- Fabricating the final product in an easy way and in a relatively short time

- $\quad$ First-hand experiencing additive manufacturing and its potential

\section{Q3 - Drawbacks}

What were the difficulties or drawbacks that you encountered?

Responses from students that self-identified with the CAD role

- Dissolution of supporting material and structures was problematic because of small clearances between moving parts

- $\quad$ Problems were encountered in the use of the CAD software because of inexperience and insufficient skill

- Because of the scaling operation to fit the part in the AM machine working volume, the part thickness was extremely low

- Difficulties in the fabrication of moving parts because on the 3D model one does not realize how much clearance is assigning for the correct motion of the elements

- Only once the AM machine failed in providing and depositing the support material, so the manufactured part was discarded

- Main difficulties in assigning the clearances to moving parts. The proper motion of the moving elements on the manufactured product was compromised by too tight clearances

- Difficulties in designing a component to be manufactured by a technology (FDM) that is unfortunately little treated in the other courses

- The need of a new design approach that takes into consideration the part having lower resistance because of the layer by layer manufacturing that is also a less accurate process

- $\quad$ Post-processing for support removal was critical when operated by hand, especially in areas of small thickness

- Difficulties in redesigning and testing of some kinematics

- The biggest challenge was to understand how to redesign the component for additive manufacturing, highlighting the differences compared to the original model

Responses from students that self-identified with the Manufacturing role

- $\quad$ None, except for some faulty FDM jobs

- The AM machine failed the first time we tried to fabricate the part

- Defects on the smallest details of the parts, such as pins and holes that were not manufactured correctly 
Table A5 continued

Responses from students that self-identified without a specific role

- Defining the clearance for the desired kinematic by considering the process tolerances of the AM machine for the large number of moving elements that were integrated in the assembly

- The manual operation of supports removal was critical, since in some cases it originated risk of damaging the small gears

- I thought I had a good knowledge of the CAD software, but I was wrong

\section{Q4-Changes}

If you had the possibility to work on the project again, what would you change?

Responses from students that self-identified with the CAD role

- The AM machine, because there are better machines that are faster and more accurate

- The orientation of the part inside the working volume of the AM machine, so as to minimize the amount of support material needed

- I would increase the size of the gears to improve their meshing because their teeth on the manufactured part are too small

- After looking at the additive manufacture parts, I would probably change clearances by reducing them in some areas and increasing them in others

- Honestly nothing, but at worst I would modify the locking system because it resulted too fragile during the assembling operation

- I would increase the thickness of the levers for a greater resistance of the mechanism

- After looking at the additive manufacture parts, I would improve the design

- Some tolerances of the components

Responses from students that self-identified with the Manufacturing role

- $\quad$ The geometry of parts

Responses from students that self-identified without a specific role

- The geometry and thickness of certain components in order to avoid breakage

- Increasing the thickness slightly and including a greater number of holes or slots for removal of the supporting material from the assembly interior

- The dimensions of the piece to make it more resistant to breakage

\section{Q5 - Suggestions}

What are your suggestions for the CAP practice in the years to come?

Responses from students that self-identified with the CAD role

- Add new AM machines to the laboratory

- To propose the experience again and possibly to show live also other techniques different from FDM

- To dedicate more time to the redesign activities by reporting some targeted examples

- To start the project with a reverse engineering approach by 3D scanning a physical part to be re-designed

- To provide more design guidelines and detailed examples ) and to include an analysis of production costs.

Responses from students that self-identified with the Manufacturing role

- To use a machine with better performances

- To use other AM technologies for the various teams to speed up the production, but also to allow for comparisons between different AM processes 
